\title{
Numerical Simulation on Damage and Failure Mechanism of Rock under Combined Multiple Strain Rates
}

\author{
Wancheng Zhu (D), Jiong Wei, Leilei Niu, Shuai Li, and Shaohua Li \\ Center for Rock Instability and Seismicity Research, School of Resource and Civil Engineering, Northeastern University, \\ Shenyang 110819, China
}

Correspondence should be addressed to Wancheng Zhu; zhuwancheng@mail.neu.edu.cn

Received 5 January 2018; Accepted 12 March 2018; Published 11 October 2018

Academic Editor: Caiping Lu

Copyright (c) 2018 Wancheng Zhu et al. This is an open access article distributed under the Creative Commons Attribution License, which permits unrestricted use, distribution, and reproduction in any medium, provided the original work is properly cited.

\begin{abstract}
During underground hard-rock mining, the drilling and blasting method currently remains the most economical excavation method, and the rock may experience a multistrain-rate spectrum under quasi-static, dynamic, and rheological loading conditions and their combination as well. The study on the damage mechanism of rock under multistrain-rate condition that induced by mining excavation is the fundamental issue for predicting the mining-induced hazards such as rockburst. In this study, the state of the art of rock damage and failure under different strain rates is reviewed first. Then, the numerical model for rock failure under multiple strain rates is formulated when the rock damage is taken as the main thread. Meanwhile, we summarize our work in this area over the past ten years, and the constitutive law for the damage and failure of rock under multistrain rates is presented. Finally, several numerical examples, i.e., rock damage and failure under combined static and dynamic load, rock damage and failure triggered by dynamic stress redistribution due to excavation, rock damage and failure induced by blasting, and rock damage and failure due to the combination of dynamic disturbance and rheological load, are presented. Based on these numerical simulations, the associated rock damage mechanism and failure behaviors under differently combined multiple strain rates are clarified, which may provide a theoretical basis for clarifying the rock failure mechanism during rockbursts and rock blasting. Also, further studies on the damage and failure of rock under multiple strain rates are suggested.
\end{abstract}

\section{Introduction}

The mineral resources are the material bases of economic development and national security. The depletion of shallow ore reserves is forcing human to exploit reefs at everincreasing depths [1]. Underground mining is now extracting mineral resources at the depth that would have been thought un-minable previously [2]. There are over 100 mines currently developing at depths more than $1000 \mathrm{~m}$, e.g., Tau Tona, Savuka, Mohab Khotsong, Elandsrand, and Mponeng mines in South Africa; Laronde, Creighton, Kidd "D," Craig, and Fraser mines in Canada; Enterprise, Mount Magnet Hill 50, Otter-Juan, and Perseverance mines in Australia; Galenna, Sun shine, and Henderson mines in America; Champion Reef, Nundydroog, and Mysore mines in India; and Kristineberg, Kiirunavaara, and Malmberget mines in Sweden [2, 3]. In China, Hongtoushan, Dongguashan, Huize, Fankou, and Zhaogezhuang mines are also developed below $1000 \mathrm{~m}$. In future, more and more mines will go deeper and deeper in China.

Deep mining is a very challenging task, where the underground rockmass is under the so-called H3-D1 (e.g., high geo-stress, high geo-temperature, high fluid pressure, and strong mining-induced disturbance) conditions [4]. In this respect, the $\mathrm{H} 3$ environment is the natural hotbed for mining-induced hazards, while D1-induced multistrain-rate disturbance induced by excavation is the key artificial factor to trigger the mining-induced hazards. As for underground mining, the drilling and blasting method currently remains the most economical excavation method for underground hard-rock mining, which poses one of the most important dynamic disturbances. In terms of rockburst in deep mining, 
it is generally acknowledged that the main reason for the rockburst is the abrupt release of elastic strain energy [5]. However, the sufficient strain energy is the only prerequisite of the rockburst; in this respect, D1 (mining-induced disturbance) is the key factor to trigger the rockburst [6-8]. Deep rockmass is usually under a state that transits from stable to unstable equilibrium; it is prone to rockburst due to the mining-induced disturbance.

As for the dynamic disturbance of rock blasting, it is generally considered that the blasted rock is subjected to a strain rate in the range of $10^{-8}-10^{4} \mathrm{~s}^{-1}$ [9]. Both the theoretical study and field investigation indicate that it takes only several to tens of milliseconds for the formation of a new open surface [10]. Hence, during underground excavation, the release of in situ stress can induce a strong unloading wave to the surrounding rockmass. Blasting excavation changes the rockmass structure of the mining area, which causes the stress redistribution of the surrounding rockmass. The local stress concentration can induce the damage and fracture and even failure of the rockmass, especially in deep mining. This phenomenon reflects the quasi-static effect of excavation. In addition, blasting vibration is one of the main sources of dynamic disturbance. There are many roadways and stopes are excavated in underground mines, during which the blasting may induce the vibration of existing adjacent opening. When the compressive wave reaches the free surface of rockmass, the reflected wave induces a tensile stress and tensile spalling because the tensile strength of rockmass is low [11]. This is also one mechanism associated with the rockburst triggered by dynamic disturbance $[7,8,12]$.

Moreover, mining-induced hazards such as rockburst do not always occur during blasting; instead, a large number of evidences in the field investigation suggest that rockburst often lags behind the blasting, especially in the high stress level. This is because rock has rheological characteristics, suggesting time-dependence of rockburst that is triggered by rock blasting $[1,13]$. In most cases, even though blasting vibration may not induce the instant rock failure, multiple blasting vibrations may induce the accumulation of rock damage and growth of pre-existing cracks, facilitating the rock creep. On the other hand, this phenomenon becomes more pronounced with the increase of mining depth because there is vast energy stored in the rockmass, especially in the blasting-induced excavation damage zone (EDZ). This is the mechanism for time-lagged rockburst.

In this respect, during the drilling and blasting, the blasting stress wave, blasting-induced gas pressure, transient unloading, quasi-static secondary stress, and rock rheology may all contribute to the damage and unstable failure of rockmass, which spans about 12 orders of magnitude of strain rate from rheology to impact loading [14, 15]. Therefore, the rockburst mechanism in deep mining is usually associated with the multistrain-rate damage and failure of rock under the combined dynamic, quasi-static, and rheological loading conditions, which poses a big challenge for the prediction of rockbursts. However, currently, there are few studies that could cover the multistrainrate response of rock as a whole process, either in theoretical model or numerical simulation.
In this study, when the rock damage is taken as the main thread, the state of the art of rock damage and failure induced by multistrain-rate (i.e., quasi-static, dynamic, combined static and dynamic, and rheological) conditions is reviewed first. Then, in consideration of the multistrain-rate effect of rockmass induced by deep mining, several examples, e.g., rock damage and failure under multiple strain rates ranging from rheological, quasi-static, and dynamic loading conditions, are demonstrated with numerical simulations, which may provide a theoretical basis for clarifying the mechanism of mining-induced hazards.

\section{Review of Rock Damage and Failure under Multistrain-Rate Loading Conditions}

In this section, the damage and failure of rock under multiple strain rates are reviewed, where the damage of rock is considered as the main thread. Based on this review, the general-purpose constitutive law for rock damage is presented in Section 3.

\subsection{Rock Damage and Failure under Quasi-Static Loading.} While the damage and failure of rocks is highly desirable during the excavation process, it should of course be avoided or at least controlled for the safety of the rock engineering [16]. For this reason, the damage and failure of rock has been one of the most important topics in rock mechanics. Much of the early work on rock mechanics is based on the theory of elasticity and failure criterion, especially for rock under quasi-static loading. However, it usually ignores the critical role of structural features of rockmass. A particularly important event in the development of the subject is the merging of elastic theory with the discontinuum approach [17]. Hereafter, the theory of plasticity, fracture mechanics, damage mechanics, fuzzy mathematics, fractal theory, grey theory, etc. are all applied to study the rock damage and failure under quasi-static loading [18].

The laboratory test is the main method to study the rock deformation and damage and failure processes. In experimental rock mechanics, important developments were made between 1945 and 1960, based on laboratory large-scaled experimental works conducted by Mogi [19]; the friction of discontinuities studied by Jaeger [20] and large-scale triaxial tests performed by Blanks and McHenry [21]. In addition, studies by Rocha et al. [22] and John [23] motivated a more common use of large-scale field shear failure testing of rock discontinuities. Carneiro [24] developed an indirect tensile method for determining the tensile strength of rock called the Brazilian test. Another important advance in rock testing was the development of stiff and servo-controlled testing machines [25]. After the establishment of the ISRM Commission on Testing Methods in 1966, a number of suggested testing methods for rock were developed and improved $[16,26]$. In addition, the applications of X-ray, SEM, infrared remote sensing, laser speckle, acoustic emission, etc. provide more effective ways for disclosing the intrinsic mechanism for rock damage and failure. 
In the aspect of numerical modeling, different numerical methods have been developed for the rock progressive failure simulation. Generally, they are categorized into two groups: continuum-based methods, e.g., finite element method (FEM), finite difference method (FDM), and boundary element method (BEM) and discontinuum-based methods, e.g., discrete element method (DEM), discrete fracture network (DFN), and discontinuous deformation analysis (DDA) $[27,28]$. There are also some hybrid methods coupling continuum and discrete approaches, e.g., hybrid FEM/BEM, hybrid BEM/DEM, and hybrid FEM/DEM. The recently developed numerical manifold method (NMM) is a promising method because it is treated as a combination of FEM and DDA [29-31]. Nowadays, the research on continuous-discontinuous simulation of rock is still a hot spot in rock mechanics.

The field study on rock mechanics problems, such as the rockburst induced by deep-level hard-rock mining, had been conducted in South Africa since 1953 [32, 33]. The similar rockburst study was experienced at the Kolar goldfield, India in the 1960s [34]. Moreover, in order to examine the excavation damaged zone (EDZ), many field laboratories were established, such as Äspö Hard Rock Laboratory (HRL) $[35,36,37]$ in Sweden, AECL Underground Research Laboratory (URL) $[38,39,40]$ in Canada, Kamaishi mine [41] and Mizunami Underground Research Laboratory [42] in Japan, Mont Terri Rock Laboratory [43, 44] and Grimsel Test Site [45] in Switzerland, Mol Underground Research Laboratory [46, 47] in Belgium, and Meuse/Haute-Marne Underground Research Laboratory [48, 49] in France. In China, the rockburst studies in the tunneling of Jinping project made significant contributions to the development of rockburst prediction $[50,51]$. Although those underground research laboratories are not designed for mining application, they provide deep insight into the rock damage in response to underground excavation.

\subsection{Rock Damage and Failure Induced by Dynamic Loading.} The principles of brittle materials such as rock and concrete under dynamic loading have been extensively reviewed $[15,52-55]$. One of the most widely used loading techniques for the purpose of performing tests and investigating dynamic behavior of materials is the SHPB device developed by Kolsky [56]. Davies [57] improved the measurement technique by utilizing parallel plate and cylindrical condenser microphones to electrically measure the stress wave. Kolsky [56] developed the split bar system, which included two bars with a specimen sandwiched in between, and obtained the dynamic relationship between stress and strain for several materials including polythene, copper, lead, and so on. Krafft et al. [58] applied a striker bar to produce a repeatable impact stress wave and the strain gauge to measure the stress waves, which has become a standard measurement technique. Lindholm [59] combined previous modifications and designed an updated version of the Kolsky bar system, which became a template of the current SHPB system. Recently, suggested methods for the dynamic SHPB test for determining the dynamic strength parameters and mode-I fracture toughness of rock materials are proposed [60].
The SHPB tests are based on two fundamental assumptions. One is the one-dimensional elastic wave propagation in the bars; the other is the stress uniformity in the rock specimen during the dynamic loading. The assumption of one-dimensional elastic wave propagation is affected by two factors: inertia effects and dispersion effects. The stress uniformity in the rock specimen is affected by inertia effects and end friction effects.

Due to Poisson's ratio effect, the stress wave propagating in SHPB tests causes inertia and influences measured mechanical properties. Davies and Hunter [61] firstly investigated the inertia effect and suggested that there exists an optimal length-to-diameter ratio to minimize it. For the inertia effect, significant progress has been conducted in experimental tests [62], theoretical investigations [63], and numerical simulations [64-66].

The end friction between the specimen and the loading device may lead to a complex stress state of multiaxial compression which influences the accuracy of the testing results. Friction effects can be lessened by minimizing the area mismatch between the specimen and the bars [67], by an optimal length-to-diameter ratio $[61,68]$ and by using lubricants [69] and ring specimens [62, 70,71].

The effects of dispersion accumulate with wave propagation over distance and the bar diameter increase. For wave dispersion, analytical, numerical, and experimental corrections were conducted [72-74]. In order to minimize the effects of dispersion and inertia for maintaining the onedimensional wave propagation and facilitate dynamic stress equilibrium in the specimen, several methods are designed to change the shape of the incident wave and slow down its rising. One way is to place a small thin disc made of soft materials between the striker and the incident bar $[75,76]$. Another way is placing a pulse shaper rod [77] or the extra sample (the same material as the tested) between the striker and the incident bar [78]. The third way is to design variable geometry of the striker. Tapered and cone-shaped strikers are used by $[60,74]$ to generate an approximate half-sine incident waveform. In this respect, half-sine incident wave is easier than rectangular wave to achieve the dynamic stress equilibrium and constant strain rate in the rock sample.

The dynamic mechanical behavior of rock materials has been extensively studied since significant progress in experimental methodology, including the dynamic compressive strength and dynamic stress-strain curve [75, 79-82], dynamic tensile strength [83-86], dynamic bending strength [87], dynamic shear strength [88, 89], dynamic triaxial strength [90, 91], dynamic fracture [92-96], and coupled compression-shear failure [97].

The strength of hard rock under dynamic loading increases with the strain rate, showing strong strain-rate dependency [83]. At lower strain rates, strength increase is very gradual and constant, and above a certain strain rate, the increase in strength with strain rate is drastic. This transition occurs at a strain rate between $10^{-3}$ and $10^{2} \mathrm{~s}^{-1}$, which may be dependent on the rock type [14] and is particularly important to determine the dynamic response of rock under the intermediate strain rate. Apparatus for intermediate strain rate $\left(10^{0}-10^{2}\right)$ testing are mainly pneumatic-hydraulic 
and completely gas-driven machines, servo-hydraulic test machine, drop-weight machine, and pendulum hammer machine. A specially designed servo-hydraulic test machine can impose strain rates up to approximately $1 \mathrm{~s}^{-1}$ [86], while the Split-Hopkinson pressure bar (SHPB) has become a commonly accepted test method for strain rates in the range of $10^{1}-10^{4} \mathrm{~s}^{-1}[88,98,99]$. Dynamic tests on sandstone for measuring dynamic tensile strength and strain rate were carried out using underwater shock waves under the strain rate ranging from 10 to $40 \mathrm{~s}^{-1}$ [100]. The pneumatichydraulic testing machine has been developed for studying the strain rate ranging from $10^{0} \mathrm{~s}^{-1}$ to $10^{1} \mathrm{~s}^{-1}$, and dropweight machines have been used to achieve strain rate ranging from $10^{0} \mathrm{~s}^{-1}$ to $10^{2} \mathrm{~s}^{-1}$ [15]. The dynamic Brazilian test of rock specimens was conducted with the pendulum hammer-driven SHPB test in order to determine the tensile strength of rock under an intermediate strain rate ranging from 5.2 to $12.9 \mathrm{~s}^{-1}$ [101].

\subsection{Rock Damage and Failure Induced by Combined Static and} Dynamic Load. During the underground excavation with the drilling and blasting method, rockmass is subjected to the high-in situ stress firstly and subsequently disturbed by the blasting, which is a process of combined static and dynamic loading. Compared to cases that are subjected to static loading or dynamic loading separately, the rock behaves differently under combined static and dynamic loading. Therefore, it is of great importance to consider the damage and failure of rock under combined static and dynamic loading, in order to clarify the rockbursting mechanism triggered by dynamic disturbance.

Christensen et al. [102] and Lindholm et al. [103] performed some of the most pioneering work subjecting the specimen to hydrostatic pressure before axial impact load. Two pressure chambers (a confining pressure vessel and an axial pressure vessel) are introduced by Frew et al. [104], where the axial pressure supplied by the axial pressure vessel and the lateral pressure supplied by the confining vessel create a hydrostatic pressure before axial impact. In addition, based on the ISTRON1342 electro-hydraulic servo testing machine, a combined static and dynamic loading testing system was developed by Zuo et al. [105].

The SHPB apparatus was modified for rock subjected to combined static and dynamic loads, which was able to study the failure of the statically loaded rock specimen subsequently triggered by dynamic disturbance under high strain rate [106-108]. The dependency of rock strength on strain rate and static stress level is examined, and the damage and failure mechanism of rock during combined static and dynamic loading were investigated. Cui [109] and Gong et al. [110] studied the mechanical response and failure characteristics of rock under three-dimensional combined static and dynamic loads, considering the effects of axial static stress, confining pressure, and dynamic stress. Li et al. [111] found that the strengths of rock material under coupled static and dynamic loads are generally higher than the uniaxial static compression strength and dynamic strength under only impact loads. The mechanisms associated with the increase of dynamic strength of rock subjected to the combined static and dynamic loading are clarified using the simulator RFPA-Dynamics by Zhu et al. [112]. Jia and Zhu [12] studied the rockburst mechanism in jointed rock mass under dynamic load based on coupled static-dynamic analysis. Zhou et al. [113] investigated the dynamic tensile behavior of granite rocks under combined static and dynamic loads using the Brazilian disc. Wu et al. [114] studied the influence of static pre-tension on the dynamic tensile failure of rocks and found that the dynamic tensile strength decreases with the increase of the pre-tension. Liu et al. [115] studied the influence of bedding direction on the strength of rock under combined static and dynamic uniaxial compressions. Wu [116] reported an experimental observation of the slip initiation of granular gouge friction in a rock discontinuity triggered by static and dynamic loads at a wide range of loading rates. Zou et al. [117] studied different mechanical and cracking behaviors of single-flawed brittle gypsum specimens under dynamic and quasi-static loading.

2.4. Rock Damage and Failure Induced by Blasting. The drilling and blasting method has been widely used in underground excavation and construction, and it is still a popular method of rock fragmentation. So, blasting is the major source of dynamic loads in rock engineering. Proper design and control of blasts as well as prediction of blasting results has become imperative in many operations. Therefore, a lot of works are done on damage and failure during rock blasting.

Some investigators consider the major portion of fragmentation to be caused by the initial explosive stress pulse $[118,119]$. Others think the action of the gas pressure plays a dominant role in the rock-blasting process [120, 121]. Afterwards, a comprehensive theory concerned with the combined effects of both stress wave and gas pressure and their interaction is devised [122]. In order to clarify the respective roles of stress wave and gas pressure in the rock fragmentation during blasting, Kutter and Fairhurst [122] studied the fracture process around the borehole by separating the two principal blast forces. The gas pressure was shown to play an important role in blasting, but it was also shown to be only effective if the cavity and free surface have been preconditioned by the stress wave. Hereafter, many studies have revealed that the stress wave is responsible for initiation of the crushing zone and the surrounding radial fractures, while the gas pressure further extends the fractures (Figure 1) [123-125].

As for the excavation-induced response of rock blasting, as early as 1966, Cook et al. [126] pointed out that the impulsive release of load during excavation could cause the over-relaxation of the loaded rock, generating tensile stresses. Abuov et al. [127] pointed out that the unloading wave was induced with the formation of a new free surface, and a rockburst might occur when the potential energy of compression reached a specific level. Cai [18] deemed that, in addition to blasting stress wave and blasting gas pressure, dynamic unloading was another factor that contributed to the blasting-induced rock damage. Zhou and Qian [128] and 
(a) Crushing

(b) Crushing and fracture in non-linear zone

(c) Radial cracks from elastic wave
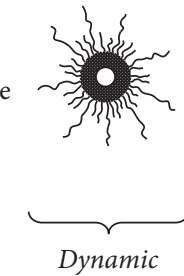

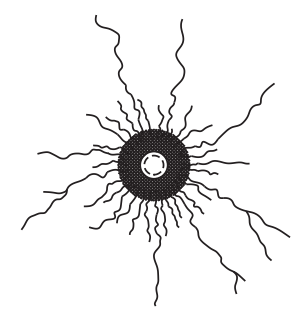

(d) Extension of non-linear crushed zone Growth of radial fractures

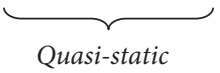

FIgURE 1: The evolution of fracture patterns at the consecutive stages in the fracture process of one-borehole blasting [122].

Li et al. [129] took the stress redistribution as a dynamic process to interpret the tension-compression alternation and zonal disintegration phenomena around the deep tunnel. Lu et al. [10] studied the process of in situ stress release accompanying rock fragmentation by blasting and the dynamic response of rockmass induced by the transient unloading. Tao et al. [130] investigated the unloading failure mechanisms of hard rock in a confined state during the unloading process. Zhu et al. [131] revealed transient unloading could cause tensile stress near the free excavation surface, which might result in tensile failure of the surrounding rockmass. Fan et al. [132] discussed the influence of unloading rates on the strain-burst characteristics during the excavation of deep-rockmasses. Li et al. [133] studied the influence of unloading disturbance on the adjacent tunnel. Yang et al. [134] investigated the influences of blast loading, dynamic unloading, and the combined effects on the rockmass vibrations, respectively.

During rock blasting, the blasting-induced responses, e.g., rock fragmentation, failure pattern, and excavation damage zone are what we concerned most. In the laboratory and field experiments, Bergmann et al. [135] investigated the effects on blasting results of explosive energy, pressure, detonation velocity, and density as well as the effects of geometric factors such as burden distance. Fourney et al. [136] studied the effect of stemming on crater-blasting fractures and assessed the validity of small model testing to predict results for larger-cratering tests. Badal [137] studied the controlled blasting in jointed rocks to explain the explosive-induced damage and failure development. Cho et al. [138] investigated the effect of the notched guide hole on failure pattern control in blasting. Saiang [139] investigated the blast-induced damaged zone around excavations and rock parameter sensitivity. Lu et al. [140] analyzed the influence of excavation sequence on the propagation of cracks during contour blasting. Zhu et al. [141] observed the crack distribution of concrete specimens subjected to high-pressure air blasting. Zhang et al. [142] developed a system for blasting under static stress and investigated the influence of static stress on explosion crater.

Numerical approaches were widely used to study the rock blasting. Grady and Kipp [9] thought that the dynamic fracture of rock-like materials is a process of continuous accumulation of damage, which promoted the research of rock dynamic failure mechanism. Yang et al. [143] developed a blast damage model to model rock damage resulting from impulsive loading which can reproduce the field observation well. Hao et al. [144] developed an anisotropic damage constitutive model to simulate the propagation of blasting stress wave and associated rock damage. Ding and Zheng [145] developed a blasting model fit for loosening blasting and achieved the simulation of blasting vibration. Zhu et al. [146] simulated the rock blasting-induced crack initiation and propagation using Autodyn ${ }^{2 \mathrm{D}}$ and discussed the influence of blasting parameters on the rock-blasting results. $\mathrm{Ma}$ and An [147] simulated the blasting-induced rock fractures using LS-DYNA and explored the influences of the key parameters on the rock failure pattern during the smooth blasting. Ning et al. [148] modeled blast-induced rockmass failure via the discontinuous deformation analysis (DDA). Yilmaz and Unlu [149] took into account four different explosive-rockmass combinations to investigate blast-induced damage zones. Yan et al. [150] modeled the dynamic cracking and casting process of bench blasting with consideration of blasting fragmentation size using the three-dimensional distinct element code (3DEC). An et al. [151] implemented a hybrid finitediscrete element method (FEM-DEM) to simulate rock fracture and resultant fragment muck piling in various blasting scenarios.

Currently, it is generally agreed that the rock around the blast hole is subjected to the following phases of loading: (a) dynamic loading, during detonation of the explosive charge, and generation and propagation of the stress wave in the medium; (b) quasi-static loading, under the residual blasthole pressure applied by the explosion gas; (c) release of loading, during the period of rock displacement and relaxation of the transient stress field [11]. Based on the above literature reviews, in this study, we attempt to characterize the rock-blasting damage as a gradual multistrain-rate process with a general-purpose damage-based model, in order to numerically simulate the rock damage and failure induced by blasting.

2.5. Rock Damage and Failure under Rheological Load. It is generally considered that rheology is one of the key reasons inducing the instability of the surrounding rockmass. Laboratory tests and in situ rheological observations are the major methods employed to study time-dependent behavior of rock [152]. Three regimes are usually observed during brittle creep experiments (when the measured strain is plotted against time): primary creep or transient creep (with decelerating strain rate), secondary creep or steady-rate creep (with constant strain rate), and tertiary or accelerating creep (with accelerating strain rate) [153-155]. During primary creep, the strain rate usually decreases as a power law of the time since the stress change [156]. The strain rate during secondary creep is nearly constant and strongly depends on the applied stress. Usually, an exponential law 
and a power law provide a good fit to experimental measurements of the strain rate during steady-rate creep $[156,157]$. In this regard, Brantut et al. [158] indicated that the strain rate during the so-called secondary creep is, in fact, never constant; it is simply an inflection period during which the strain rate remains close to or at its minimum for an extended period of time. They suggested using a decelerating and an accelerating portion to describe the creep curve [158]. During tertiary creep, creep experiments on heterogeneous materials have revealed a power law acceleration of the strain rate [159-161]. In this respect, a power-law model has been applied to fit the tertiary creep curves for a series of experiments with different constant applied differential stresses $[162,163]$. Creep tests have also been carried out on soft rocks such as lignite, tuff, shale, and sandstone, medium-hard rocks such as limestone, marble, and rock salt, and hard rocks such as andesite and granite [153, 156, 164-170]. These experiments were mostly conducted under uniaxial compression. There are few studies using creep tests under a tensile-loading regime [171].

Although the laboratory experiment is the fundamental prerequisite for our understanding of time-dependent deformation of rocks, some experiments can be rather unfeasible in laboratory due to the complexities and difficulties in performing them and the unacceptably long test period. A number of approaches have been developed to model the time-dependent deformation of rocks. In general, creep models can be divided into two categories: phenomenological approaches and micromechanical approaches [172]. It should be noted that these approaches can often be cooperative rather than competitive.

Phenomenological models are developed on the basis of empirically observed internal variables [173] or the superposition of several viscous and elastic elements $[174,175]$. Constitutive laws, based on laboratory experiments, provide a relation between strain, stress, and strain rate [173-180]. These models are normally defined using a logarithmic function, a power function, and other differential equations to reproduce the behavior of different types of rocks under different loading conditions (creep, constant stress rate, or strain rate). However, the inherent physical mechanisms of creep deformation are not accommodated in empirical models, so the key mechanical parameters remain unclear in physics. In the aspect of component models, they included the linear superposition of some viscous and elastic elements, such as the linear Burgers body [171]. But none of these linear models can explain the stage of nonlinear- and unstable-accelerating creep. In order to explain this phenomenon, more complex models with a battery of Newtonian elastic and viscous elements are required [181]. However, the separation of deformation into elastic, plastic, and viscous components can be difficult to achieve [182].

Micromechanical models, based on a suitable analysis of subcritical microcracking within fracture mechanics, may contribute a link between the microcracking and macroscopic creep response [172]. Costin [183] proposed a microcrack model to represent the time-dependent deformation and failure of rock by introducing subcritical damage laws. Kemeny [184] developed a micromechanical model for subcritical crack propagation, by incorporating Charles' power law relation into a sliding crack model. The model reproduces the trimodal form of the creep curve, indicating that there is a critical density of microcracks at the onset of tertiary creep and realizing the time-to-failure prediction. Lockner and Madden [185] proposed a numerical model of multiple-crack interaction to simulate the failure process in solid materials containing a number of flaws. Lockner [156] derived a time-dependent model for the temporal evolution of strain and reproduced empirical laws between strain rate and stress during secondary creep. Golshani et al. [186] developed a micromechanics-based numerical model to examine the time-dependent microcracking and the evolution of the excavation damage zone (EDZ) around an opening. Konietzky et al. [187] proposed a numerical cellular automata approach based on subcritical crack propagation to predict the rock lifetime. Main [163] further developed the mean-field theory of damage mechanics and suggested a simple damage mechanics model for the apparently trimodal behavior of the strain and event rate dependence, by invoking a phase of strain hardening involving distributed crack damage and a phase of strain softening involving crack interaction and coalescence. Turcotte et al. [188] proposed a one-dimensional model based on a simple damage criterion. Amitrano and Helmstetter [189] proposed a numerical approach based on the one-dimensional model of Turcotte et al. [188] to model the time evolution of strain (three-creep phases), as well as the progressive damage localization before failure, by introducing an empirical time-to-failure law and the intrinsic heterogeneities of rocks at the microscale. Brantut et al. [190] developed a micromechanical model to describe the timedependent creep of water-saturated rocks under triaxial stress conditions. In this model, the incremental strains due to the extension of cracks in compression are derived from the sliding wing-crack model of Ashby and Sammis [191], and the crack length evolution is calculated according to Charles' law. Xu et al. [192] proposed a two-dimensional numerical rheological model by using an exponentialsoftening law for the time-dependent brittle deformation of heterogeneous brittle rock under uniaxial loading conditions.

\subsection{Rock Damage and Failure under Combined Rheological} Load and Dynamic Disturbance. The time-dependent effect of deformation, damage, and failure of deep rockmass is significant, even in hard rock [1], which is considered as one of the most mechanisms for the delayed rockburst. Based on the instability analysis of plate and beam structures according to viscoelastic theory, Zhang [193] qualitatively explained the time-lagged rockburst. Xu et al. [194] discussed the occurrence prerequisite and time of rockburst in rheological strata. These two theoretical models demonstrate the time-lagged instability triggered by dynamic disturbance.

In mining practice, time-delayed rockburst is considered to be closely related to rock damage after blasting. Even if blasting excavation may not trigger rockburst immediately, 
rockbursts often occur after it. The relationship between rockburst and blasting vibration in deep mining was intensively studied in South Africa [13]. The rockburst frequency within two hours after blasting was multiple times or even tens of times higher than that in other time periods. In the Hongtoushan copper mine in China, most rockbursts occurred within several hours after blasting [195]. In the construction of the auxiliary tunnel of Jinping-II hydropower station, it was also found that most of these rockburst events occurred within 2-3 hours after blasting [196]. Yan et al. [197] found that the disturbances from excavation particularly under blasting excavation have an important influence on the intensity and the scale of rock bursts. In this respect, excavation-induced rock instability, such as the time-delayed rockburst, can be considered as the unstable failure of rock under the combined quasi-static, dynamic, and rheological load.

In order to clarify the influence of dynamic disturbance on the rock rheology, Gao et al. [198] developed a testing machine to measure the response of rock under the combined rheological and dynamic loading. Zhu et al. [199] invented a stress relaxation-dynamic disturbance testing machine to study the rock damage and failure under stress relaxation and dynamic disturbance. Also, a damage-based constitutive model for rocks subjected to stress relaxation and dynamic disturbance is proposed based on damage mechanics.

Therefore, based on the above literature review, it can be concluded that it is very necessary to study the rock damage mechanism under multiple strain rates, in order to clarify the failure mechanism of mining hazards such as rockbursts.

\section{Governing Equations}

3.1. Mechanical Equilibrium Equations. The equilibrium equation for solid mechanics is given by Newton's second law. It is usually written using a spatial formulation in terms of the Cauchy stress tensor [200]:

$$
\sigma_{i j, j}+F_{i}=\rho \frac{\partial^{2} u_{i}}{\partial t^{2}} \quad(i, j=x, y, z)
$$

where $\sigma_{i j}$ denotes the stress tensor, $F_{i}$ denotes the body force per unit deformed volume, $\rho$ denotes the material density, $u_{i}$ denotes displacement, and $t$ denotes time. This equation expresses the mechanical equilibrium in rock subjected to dynamic load. It could be used for quasi-static analysis when the acceleration term in the right-hand term is specified to zero.

Under the assumption of small displacements and rotations, the normal strain components and the shear strain components are related to the displacement as follows:

$$
\varepsilon_{i j}=\frac{1}{2}\left(u_{i, j}+u_{j, i}\right)
$$

where $\varepsilon_{i j}$ denotes the strain tensor.

For rocks under static or dynamic loading, the behaviors of them are assumed to be linear elastic. The strain tensor follows Hooke's law:

$$
\varepsilon_{i j}=\frac{1+v}{E} \sigma_{i j}-\frac{v}{E} \delta_{i j} \sigma_{m m} \quad(i, j, m=x, y, z),
$$

where $E$ denotes Young's modulus, $v$ denotes Poisson's ratio, and $\delta_{i j}$ denotes Kronecker function $\sigma_{m m}=\sigma_{x}+\sigma_{y}+\sigma_{z}$.

For rocks under rheological load, the behaviors of them are assumed to be nonlinear elastic. The strain tensor can be expressed by [198, 200]

$$
\varepsilon_{i j}=\frac{1+\nu}{E} \sigma_{i j}-\delta_{i j} \frac{\nu}{E} \sigma_{m m}+\varepsilon_{i j}^{c},
$$

where $\varepsilon_{i j}^{c}$ is the creep strain tensor. The creep strain rate is defined by [202]

$$
\frac{\partial \varepsilon_{i j}^{c}}{\partial t}=\frac{3}{2} S_{i j} A n_{0} \sigma_{\mathrm{e}}^{m_{0}-1} t^{n_{0}-1},
$$

where $S_{i j}$ is the deviatoric stress tensor, $A, m_{0}$ and $n_{0}$ are experimentally determined parameters, and $\sigma_{\mathrm{e}}$ is the effective stress, defined as

$$
\begin{aligned}
\sigma_{\mathrm{e}}= & \left(\frac{1}{\sqrt{2}}\right) \\
& \cdot \sqrt{\left(\sigma_{x}-\sigma_{y}\right)^{2}+\left(\sigma_{y}-\sigma_{z}\right)^{2}+\left(\sigma_{x}-\sigma_{z}\right)^{2}+6\left(\sigma_{x y}^{2}+\sigma_{x z}^{2}+\sigma_{y z}^{2}\right)} .
\end{aligned}
$$

Differentiating Equation (4) with respect to time, the strain rate can be described by

$$
\frac{\partial \varepsilon_{i j}}{\partial t}=\frac{1+\nu}{E} \frac{\partial \sigma_{i j}}{\partial t}-\delta_{i j} \frac{\nu}{E} \frac{\partial \sigma_{m m}}{\partial t}+\frac{3}{2} S_{i j} A n_{0} \sigma_{e}^{m_{0}-1} t^{n_{0}-1} .
$$

3.2. Damage Evolution Equation. As illustrated in Figure 2, the damage of the medium in tension or shear is initiated when its state of stress satisfies the maximum tensile stress criterion or the Mohr-Coulomb criterion, respectively, as expressed by

$$
\begin{aligned}
& F_{1} \equiv \sigma_{1}-f_{\mathrm{t} 0}=0 \text { or } \\
& F_{2}=-\sigma_{3}+\sigma_{1}\left[\frac{(1+\sin \phi)}{(1-\sin \phi)}\right]-f_{\mathrm{c} 0}=0
\end{aligned}
$$

where $f_{\mathrm{t} 0}$ and $f_{\mathrm{c} 0}$ are uniaxial tensile and compressive strength $(\mathrm{Pa})$, respectively, $\phi$ is internal frictional angle, and $F_{1}$ and $F_{2}$ are two damage threshold functions.

According to the elastic damage theory, the elastic modulus of an element degrades monotonically as damage evolves, and the elastic modulus of the damaged material is expressed as

$$
E=(1-D) E_{0} \text {, }
$$

where $D$ represents the damage variable and $E$ and $E_{0}$ are the elastic moduli of the damaged and the undamaged material $\mathrm{Pa})$, respectively. In this kind of numerical simulation, the element as well as its damage is assumed isotropic, so $E, E_{0}$, and $D$ are all scalar. According to Figure 2, the damage variable can be calculated as [203] 


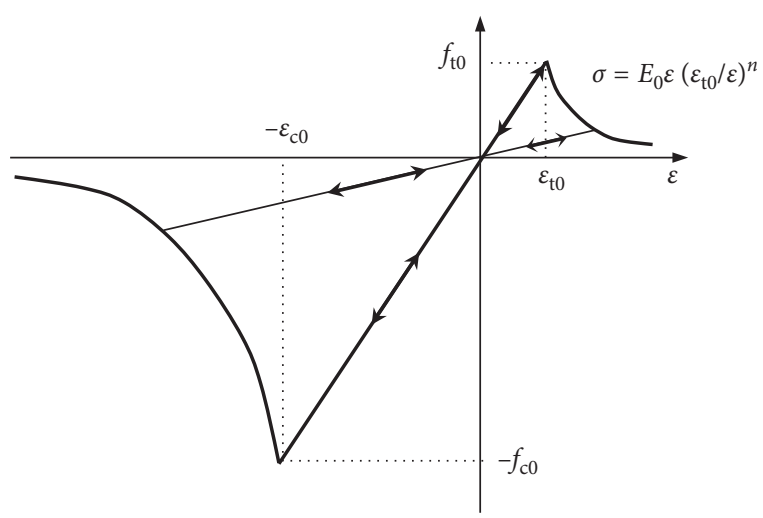

FIgURE 2: The elastic damage-based constitutive law under uniaxial stress condition.

$$
D= \begin{cases}0, & F_{1}<0 \text { and } F_{2}<0, \\ 1-\left|\frac{\varepsilon_{t 0}}{\varepsilon_{1}}\right|^{n}, & F_{1}=0 \text { and } d F_{1}>0, \\ 1-\left|\frac{\varepsilon_{c 0}}{\varepsilon_{3}}\right|^{n}, & F_{2}=0 \text { and } d F_{2}>0,\end{cases}
$$

where $\varepsilon_{\mathrm{t} 0}$ and $\varepsilon_{\mathrm{c} 0}$ are maximum principal strain in tension and maximum principal strain in compression when damage occurs, respectively, and $n$ is a constitutive coefficient, and it is 2.0. In this respect, the damage variable calculated with Equation (10) is always from 0 to 1.0 regardless of what kind of damage it may suffer. However, in the damage zone figure, in order to distinctly display the two kinds of damage modes (i.e. tensile damage and shear damage); the tensile damage is represented as negative numbers, while the shear damage is represented as positive ones.

Equations (1)-(10) are implemented into COMSOL Multiphysics, a partial differential equation-based finite element modeling environment. Thus, the damage and failure process of rocks under multiple strain rates is studied. The validation of the numerical model and its numerical implementation has been presented in the previous publications [141, 199, 201].

The above damage model was also implemented into the RFPA (rock failure process analysis) code and was used to study the failure process of rock under multiple strain rates $[125,203]$. RFPA-Dynamics is one of the RFPA versions in simulating the rock dynamics problems. As suggested in $\mathrm{Zhu}$ and Tang [203], RFPA is effective in simulating the rock failure under quasi-static and dynamic loading when the rock heterogeneity is incorporated into the model. In this respect, the damage and failure process of rock can be vividly simulated and presented graphically, which facilitates clarifying of the rock failure mechanism.

\section{Numerical Examples}

4.1. Rock Damage and Failure under Combined Static and Dynamic Loading. The damage and failure process of rock under combined static and dynamic loading under the SHPB test is simulated by using RFPA-Dynamics. The model used for the numerical simulation is shown in Figure 3. The rock specimen is sandwiched between two steel bars (incident bar and transmission bar), and the stress is applied at the top surface of the incident bar. The incident strain measured during a SHPB test is used as the boundary input for the numerical simulation.

As shown in Figure 3, the history of the incident stress $\left(\sigma_{\mathrm{i}}\right)$, reflected stress $\left(\sigma_{\mathrm{r}}\right)$, and transmitted stress $\left(\sigma_{\mathrm{t}}\right)$ can be obtained from the numerical simulation, in which the incident stress $\left(\sigma_{\mathrm{i}}\right)$ and reflected stress $\left(\sigma_{\mathrm{r}}\right)$ are retrieved from the stress history at Point B $(25,100)$, and the transmitted stress $\left(\sigma_{t}\right)$ is from Point $F(25,400)$. In this study, the stresses retrieved with different methods are compared, where $\sigma_{\mathrm{s}}\left(=\left(\sigma_{\mathrm{i}}+\sigma_{\mathrm{r}}+\sigma_{\mathrm{t}}\right) / 2\right)$ is calculated, and $\sigma_{\text {ave }}$ is stress averaged over 5 typical points in the specimen (Figure $3(\mathrm{c})$ ).

In Figure 4, the incident and reflected strains retrieved at Point $C(25,200)$ and the transmitted strain retrieved at Point F $(25,400)$ are obtained from the numerical simulation and compared to the SHPB test results. The reflected wave is especially well reproduced. However, the magnitude of the transmitted wave is overestimated by the numerical simulation because of the complex strain wave attenuation during rock failure. In general, the acceptable agreement between the experimental and numerical results confirms the capability of RFPA-Dynamics in reproducing the failure process of rock during SHPB tests.

When different confining stresses are applied at the lateral surface of the specimen, the dynamic increase factor (DIF) of the rock strength calculated using $\sigma_{\text {ave }}$ varies considerably (Figure 5 ). In this case, $\sigma_{\text {ave }}$ denotes the average stress distribution in the rock specimen, which is more reasonable to describe the stress condition in the rock specimen. First, it is found that the DIF increases with the rising confining stress. Under the confining stress, the DIF characterized by $\sigma_{\text {ave }}$ increases gradually until a peak and then decreases with static stress when the static stress $p_{s}$ approaches the uniaxial static compressive strength of rock $\sigma_{c}$. In this regard, the rock strength denoted by $\sigma_{\text {ave }}$ shows a similar tendency to experimental response determined by Li et al. [204]. This variation of DIF that depends on static stress can be qualitatively explained as follows: when the static stress is low, the static stress enhances the DIF due to the confinement effect; however, under the higher-static stress that approaches $\sigma_{c}$, the static stress may induce initial damage in the rock specimen, thus leading to the decrease of DIF.

4.2. Rock Damage and Failure Triggered by Dynamic Stress Redistribution. During the excavation of underground opening, excavation may trigger sudden release of in situ stress, leading to strong disturbance to the surrounding rock masses. Some studies have revealed the necessity of studying the transient process of stress redistribution and related dynamic response. Theoretical analysis indicates that during the dynamic unloading process, radial stress undergoes several smaller fluctuations and finally remains stable in the quasi-static secondary stress field (Figure 6(a)). The dynamic 


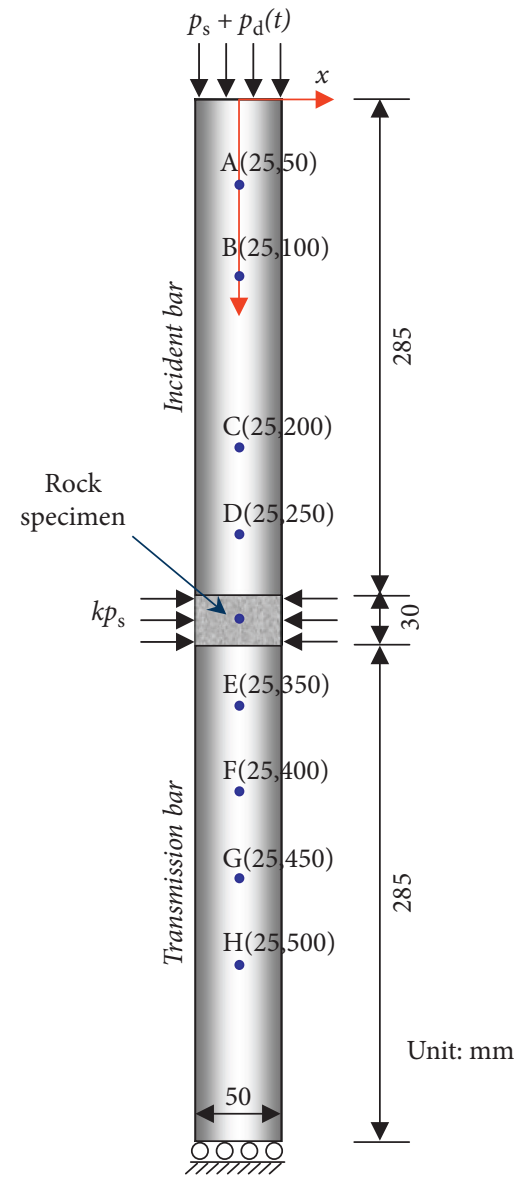

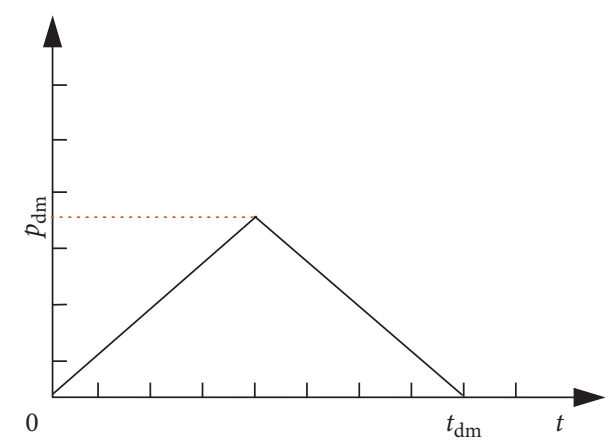

(b)

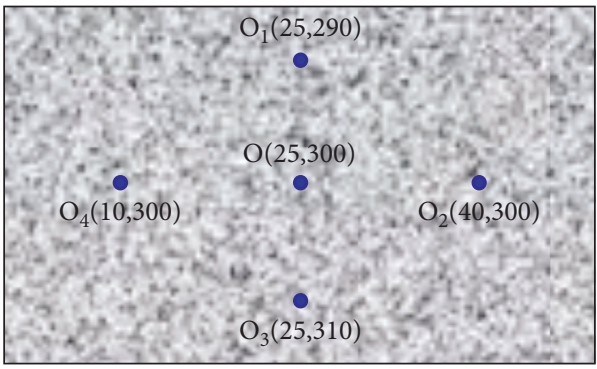

(c)

(a)

FIGURE 3: Model setup for SHPB test of rock under combined static and dynamic loading (unit: mm) [112]: (a) model; (b) the waveform of dynamic stress $p_{\mathrm{d}}(t)$ with an amplitude of $p_{\mathrm{dm}}$ and duration of $t_{\mathrm{dm}}$; (c) amplified rock specimen, in which 5 typical points where the stress or strain will be retrieved and averaged.

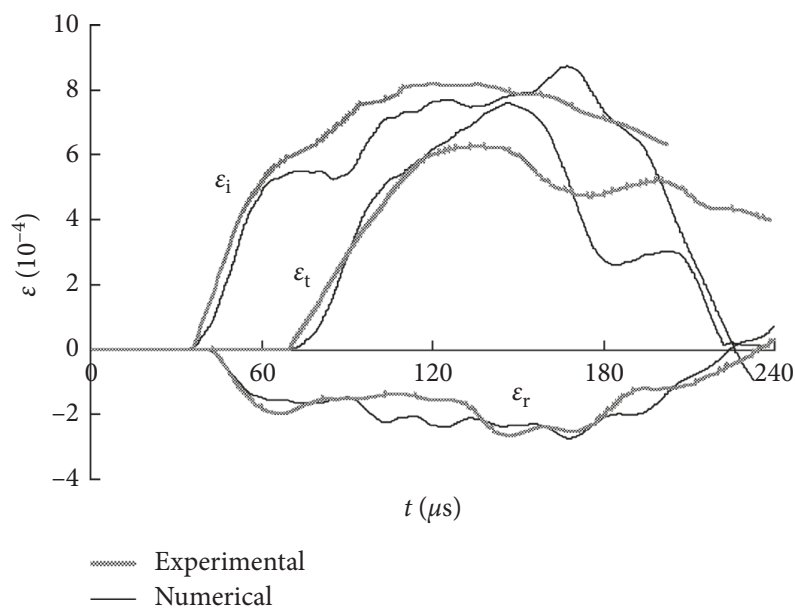

FIGURE 4: The incident strain $\varepsilon_{\mathrm{i}}$, reflected strain $\varepsilon_{\mathrm{r}}$, and transmission strain $\varepsilon_{\mathrm{t}}$ obtained from the numerical simulation and their comparison to the experimental curves [112].

unloading induced by excavation could lead to tensioncompression alternation of stress adjacent to the excavation perimeter. Tangential stress increases rapidly and then decreases, undergoing several smaller fluctuations and remains stable finally (Figure 6(b)). The dynamic effect of stress redistribution is more substantial for the shorter unloading duration. In particular, when $t_{0}$ equals to $2 \mathrm{~ms}$, the tensile stress is induced at about $4 \mathrm{~ms}$. In contrast, when 


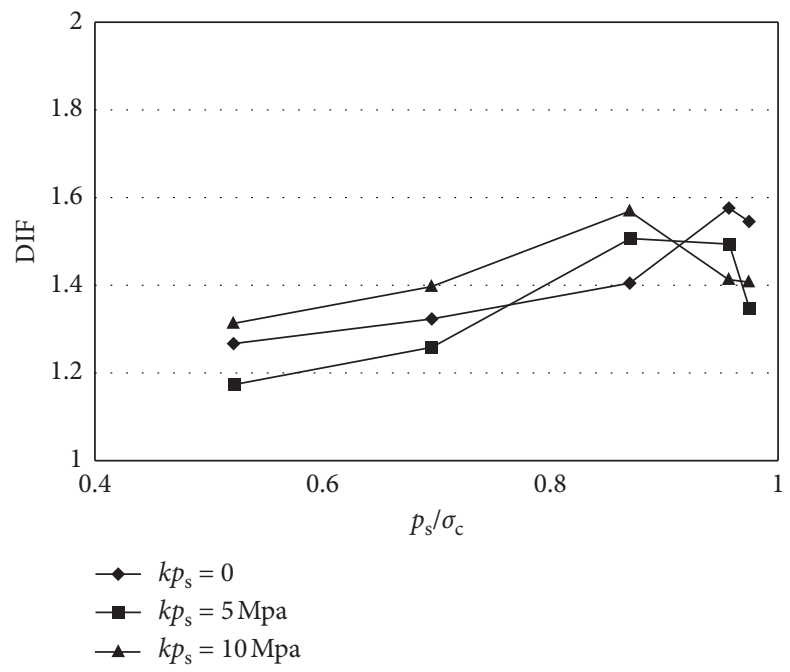

FIGURE 5: Variation of combined static and dynamic strength with static stress under different confining stress (DIF is dynamic increase factor of rock strength, $p_{\mathrm{s}}$ is the static stress, and $\sigma_{\mathrm{c}}$ is the static uniaxial compressive strength).

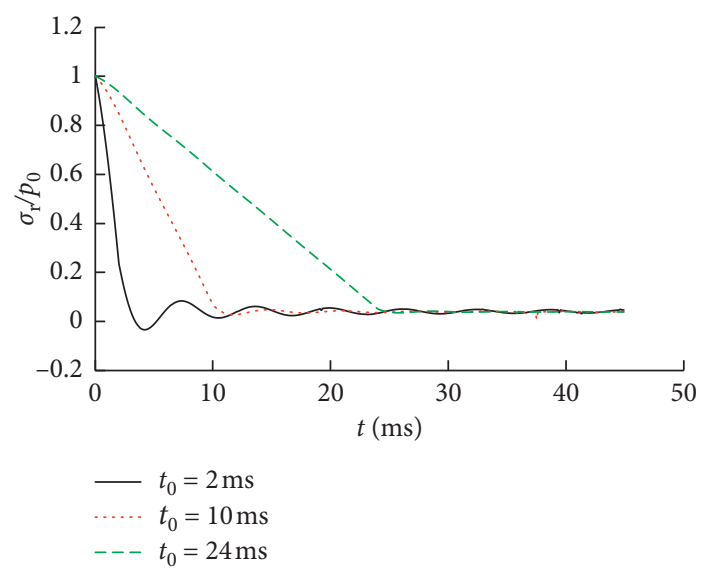

(a)

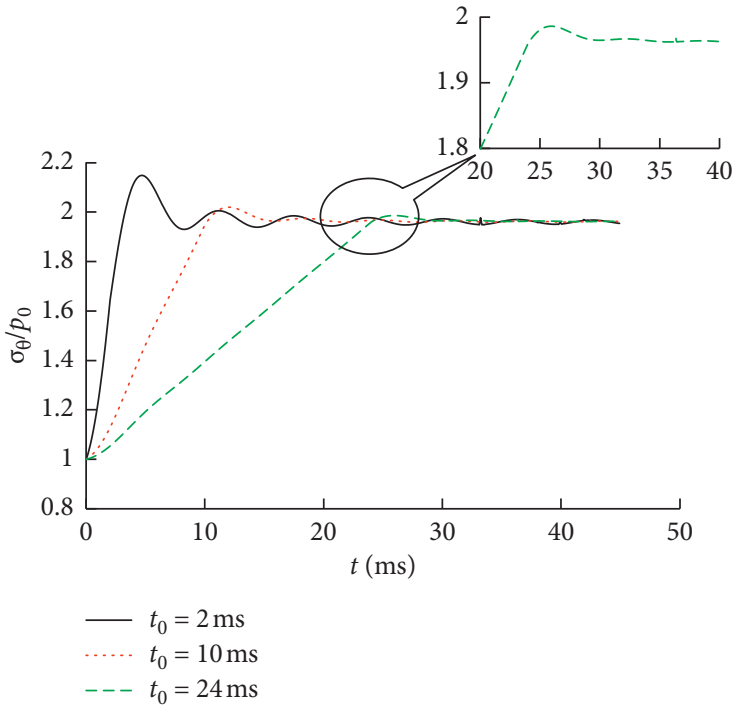

(b)

FiguRE 6: Analytical solution to time history of stress for different unloading durations (at $r=5.1 \mathrm{~m}$ and $p_{0}=-25 \mathrm{MPa}$ ) [131]: (a) radial stress and (b) tangential stress.

$t_{0}=24 \mathrm{~ms}$, the dynamic effect could be negligible, and thus tensile stress is never found.

The consideration of dynamic unloading during the numerical simulation can increase the extent of the damage zone, which may become larger with the shorter unloading duration. For instance, as shown in Figure 7, the depth of the damage zone may increase to $12.1 \mathrm{~m}$ and $13.4 \mathrm{~m}$ when the dynamic unloading with the duration of $24 \mathrm{~ms}$ and $2 \mathrm{~ms}$ is considered.

4.3. Rock Damage and Failure Induced by Blasting. A damage model for rock blasting is developed, in which the blasting process is considered as two consecutive stages, i.e., the dynamic stage caused by the stress wave and the static stage caused by explosion gas pressure. As shown in Figure 8, the blasting-induced damage agrees well with the laboratory experiment (Figure $8(\mathrm{~d})$ ). It is confirmed that the blasting stress wave initiates the primary radial cracks (Figure $8(\mathrm{a})$ ), and the explosion gas pressure results in the increase of the crushed zone radius, extension of existing cracks, and creation of new radial cracks (Figures $8(\mathrm{~b})-8(\mathrm{c})$ ).

As shown in Figure 9, the blasting-induced crack is closely related to the in situ stress conditions, and the crack propagation direction coincides with the maximum compressive principal stress. Furthermore, the crack radius decreases with the increase of depth and in situ stress, denoting the confinement of in situ stress on the blastinginduced crack propagation in rock. 


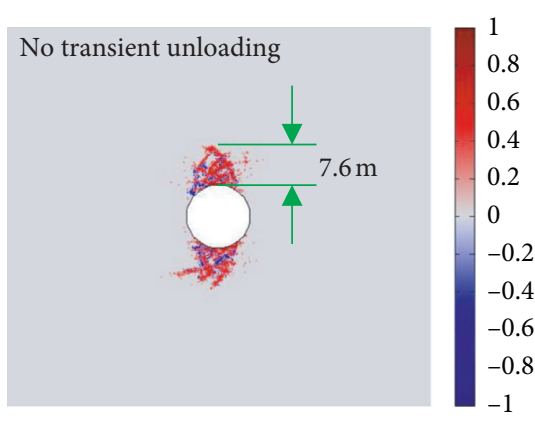

(a)

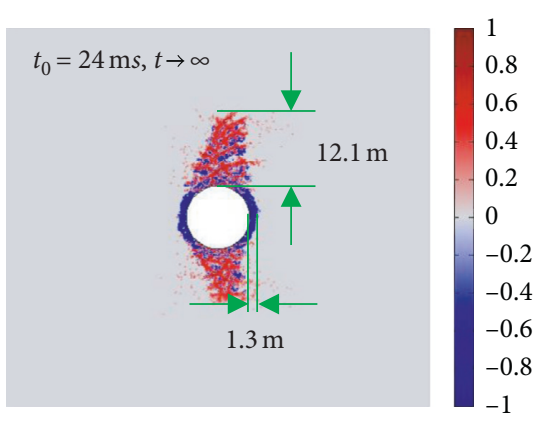

(b)

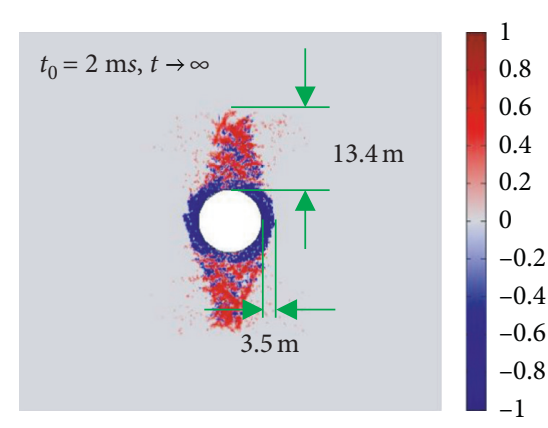

(c)

FiguRE 7: Final damage zone distribution under different unloading durations and without considering transient unloading $(\kappa=2)$ [131].

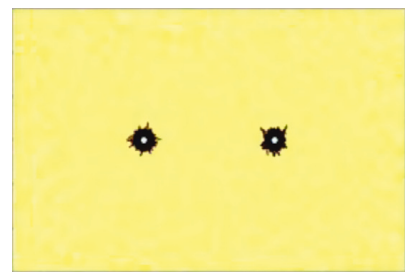

(a)

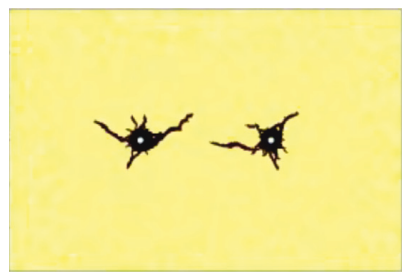

(b)

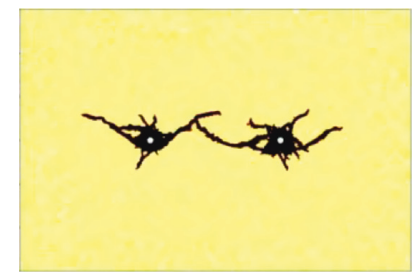

(c)

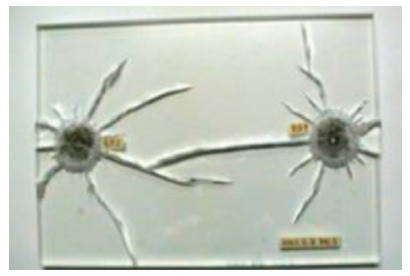

(d)

FIGURE 8: Numerical results on blasting-induced damage of rock specimens [205]: (a) step30_006; (b) step50_009; (c) step80_002; and (d) laboratory experiment.
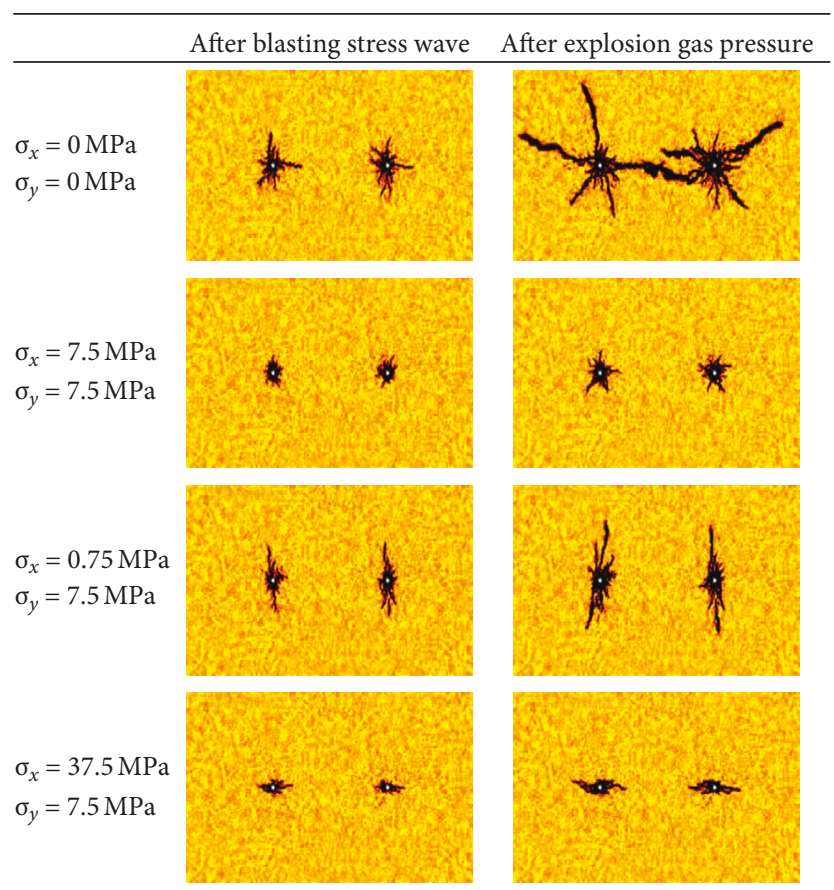

FIGURE 9: The development of rock-blasting damage under different in situ stress conditions [206].

4.4. Rock Damage and Failure Induced by Combined Rheological Load and Dynamic Disturbance. The numerical simulation on the accelerating creep of rock triggered by dynamic disturbance is conducted, in which the effect of the creep stage and waveform of dynamic disturbance on damage and failure of rock is examined. The validations of the numerical model and constitutive parameters for the rock damage under rheological load and dynamic disturbance have been presented in previous publications [201], so they are not repeated in this study.

The specific geometries and loading conditions for this model are shown in Figure 10. The numerical simulations on creep tests were performed under three stress boundaries ( $p_{\mathrm{s}}=0 \mathrm{MPa}, 10 \mathrm{MPa}$, and $15 \mathrm{MPa}$, respectively) and sustained for $12 \mathrm{hrs}$. The dynamic loading conditions is a triangle-shape stress pulse $p_{\mathrm{d}}(t)$, which is applied at the top boundary of the specimen after a constant static stress $\left(p_{\mathrm{s}}\right)$ is maintained on the specimen.

Figure 11 shows the damaged zone during the creep of rock specimens triggered by dynamic disturbance. Damage of elements induces degradation of elastic modulus, and the elements totally damaged in the tensile mode are displayed as black. It is found that the incident stress wave travels downwards along the rock specimen. When amplitude of the impact load is $10 \mathrm{MPa}$ and $20 \mathrm{MPa}$, although more new damages are created, the dispersely distributed damage did not propagate and coalesce with each other. When the amplitude $p_{\mathrm{d}}=30 \mathrm{MPa}$ and duration $p_{\mathrm{d}}=80 \mu \mathrm{s}$, in addition to the initial damage zone induced by creeping stress, the damage of several elements is induced at $t=10 \mu \mathrm{s}$. When the incident stress wave travels downwards, at $t=50 \mu \mathrm{s}$, more cracks are initiated inside the rock specimen. At $t=70 \mu \mathrm{s}$, a visible damage zone formed because of the cluster of the inner damage. At time $t=80 \mu \mathrm{s}$, the damage zones passed through the rock specimen, and therefore the rock specimen fails completely. It is concluded that the rock will become 


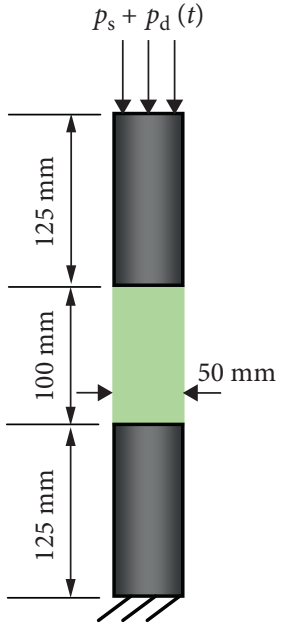

(a)

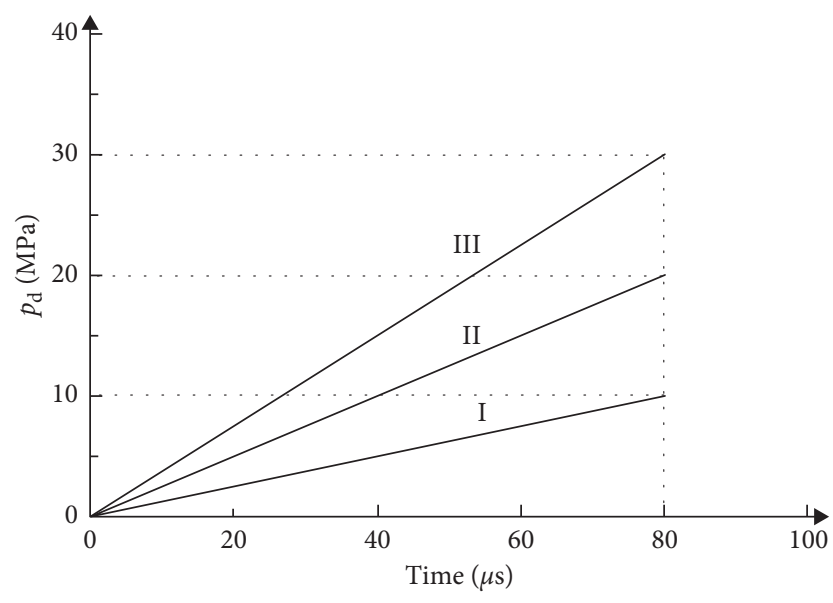

(b)

Figure 10: Numerical model for simulating rock damage and failure induced by combined rheological load and dynamic disturbance. (a) Geometries and loading conditions. (b) Incident stress waves: (I) $p_{\mathrm{d} \max }=10 \mathrm{MPa}$; (II) $p_{\mathrm{d} \max }=20 \mathrm{MPa}$; (III) $p_{\mathrm{dmax}}=30 \mathrm{MPa}$.

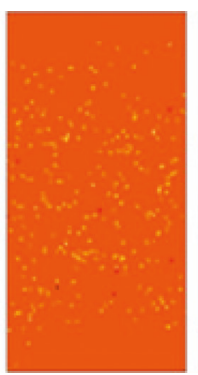

$10 \mu \mathrm{s}$

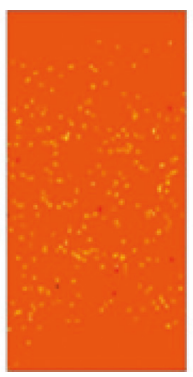

$10 \mu \mathrm{s}$

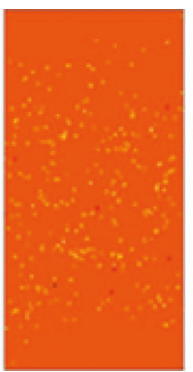

$10 \mu \mathrm{s}$

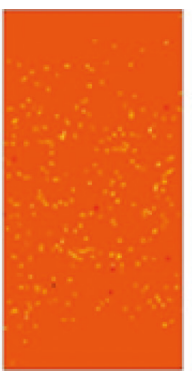

$20 \mu \mathrm{s}$

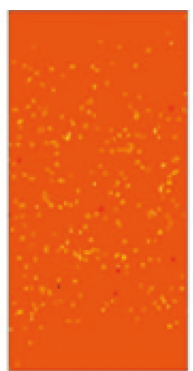

$20 \mu \mathrm{s}$

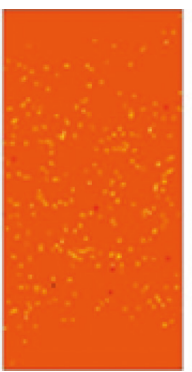

$20 \mu \mathrm{s}$

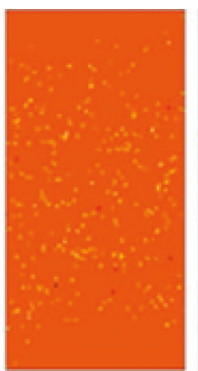

$30 \mu \mathrm{s}$

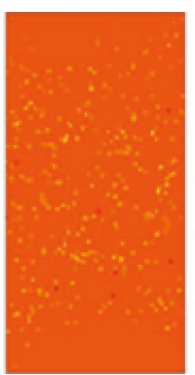

$30 \mu \mathrm{s}$

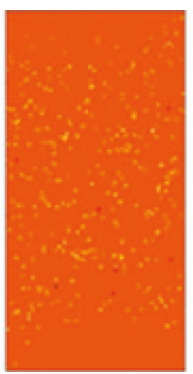

$30 \mu \mathrm{s}$

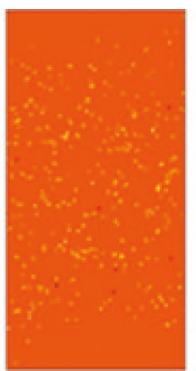

$40 \mu \mathrm{s}$

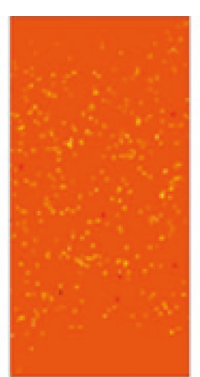

$40 \mu \mathrm{s}$

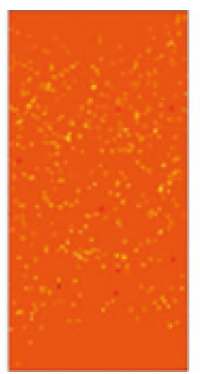

$40 \mu \mathrm{s}$

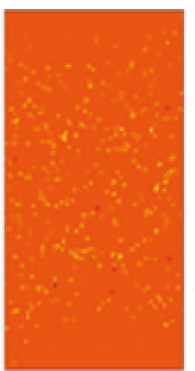

$50 \mu \mathrm{s}$

(a)

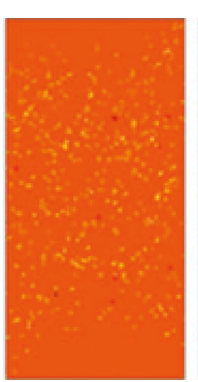

$50 \mu \mathrm{s}$

(b)

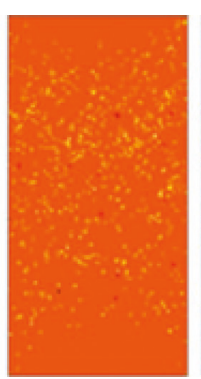

$50 \mu \mathrm{s}$

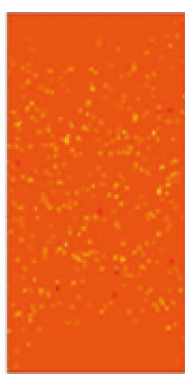

$60 \mu \mathrm{s}$

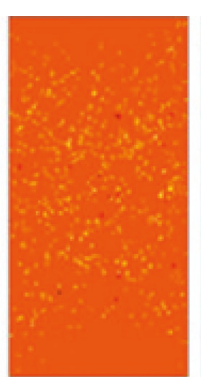

$60 \mu \mathrm{s}$

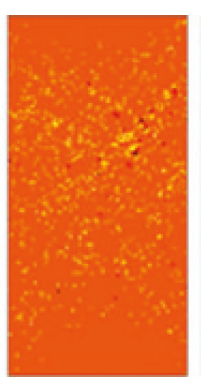

$60 \mu \mathrm{s}$

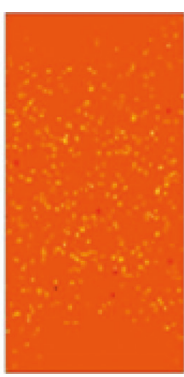

$70 \mu \mathrm{s}$

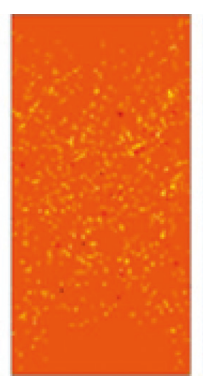

$70 \mu \mathrm{s}$

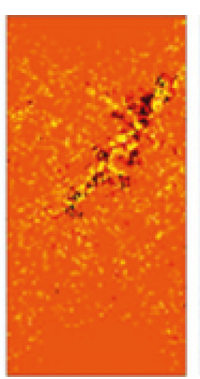

$70 \mu \mathrm{s}$

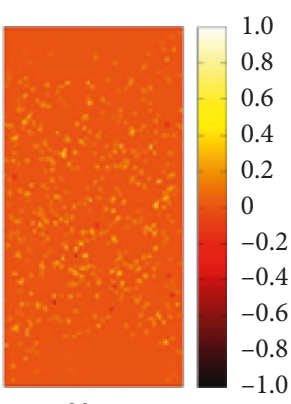

$80 \mu \mathrm{s}$

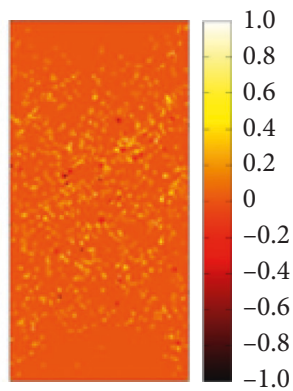

$80 \mu \mathrm{s}$

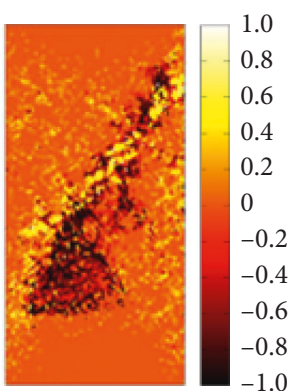

$80 \mu \mathrm{s}$

(c)

FigURE 11: The creep failure process of rock specimen triggered by dynamic disturbance: (a) impact load I $\left(p_{\mathrm{dmax}}=10 \mathrm{MPa}\right)$; (b) impact load II $\left(p_{\mathrm{dmax}}=20 \mathrm{MPa}\right) ;(\mathrm{c})$ impact load III $\left(p_{\mathrm{dmax}}=30 \mathrm{MPa}\right)$. 
more fractured with the increase of the input energy. As shown in Figure 11(c), under the higher impact loading III, at $t=80 \mu \mathrm{s}$, the shear-type macroscopic failure pattern is observed.

\section{Conclusions}

The mining-induced disturbance is characterized as a multistrain-rate condition including transient unloading, quasi-static stress distribution, dynamic disturbance, and rheological loading. In this study, the damage and failure of rock under multiple strain rates is reviewed. Meanwhile, our study on numerical models of rock damage and failure under different strain rates over the past ten years is briefly summarized. The main conclusions and outlooks are presented as follows:

(1) During the SHPB test, the strength of rock under combined static and dynamic loads is generally higher than the static uniaxial compressive strength and dynamic uniaxial compressive strength. The combined static-dynamic strength of rock increases gradually with the increase of prestatic stress; however, it may decrease when the prestatic stress approaches the uniaxial compressive strength of rock. According to the numerical simulation, the mechanism responsible for the increase of rock strength under combined static and dynamic loading is explained.

(2) In terms of rock blasting, it can be simulated as two consecutive loading stages: (a) dynamic loading applied by the blasting stress wave and (b) quasistatic loading applied by the expansion of explosion gas. The numerical simulation reproduces the initiation of cracks induced by the blasting stress wave and further propagation of cracks driven by the explosion gas pressure. Numerical simulation also indicates that the blasting-induced crack is closely related to the in situ stress conditions, and the crack propagation direction coincides with the maximum compressive principal stress.

(3) The dynamic disturbance may trigger the unstable rheological deformation of hard rock, which is considered as one of the most mechanisms for the delayed rockburst. In this respect, numerical simulation reproduces the time-dependent damage and failure of rock under combined rheological load and dynamic disturbance.

The study on the multistrain-rate effect of rock induced by deep mining provides not only important scientific significance in understanding the deformation and damage mechanism but also wide perspectives in various rock engineering applications. This study summarized the unified constitutive equations proposed by the authors to describe the multistrain-rate response of rock from the low strain rate of rheology to high strain rate of dynamic impact. However, as suggested by Jing [27]; full validation of the numerical model and numerical simulation in rock mechanics is always not possible and can at best be only partial. In this respect, our confidence in the numerical models can be raised when they are successfully calibrated against well-controlled laboratory and in situ experiments.

A lot of work needs to be done for development of this kind of damage model for rock under multiple strain rates. Firstly, some fundamental rock mechanic issues related to the multistrain-rate conditions of rock, such as strain-ratedependent failure criterion, strain-rate-dependent constitutive law, and continuous-discontinuous numerical simulation, should be studied further and validated for more loading conditions. In future, the 3D numerical simulation should be undertaken in order to capture the rock failure mechanism under real-mining conditions. Secondly, rockmass is a geological body characterized by discontinuousness, anisotropy, inhomogeneity, and not-elasticity (abbreviated as DAINE). Consequently, one of the major difficulties in the application of rock mechanics is the characterization of rockmass. This kind of numerical simulation should provide insights into the behavior of rockmasses by considering the rockmass structures and boundary conditions with chosen sophistication in rockmass parameters and engineering perturbations.

\section{Conflicts of Interest}

The authors declare that they have no conflicts of interest.

\section{Acknowledgments}

This work was funded by the National Key Research and Development Program of China (Grant No. 2016YFC0801607), National Science Foundation of China (Grant nos. 51525402, 51761135102, and 51874069), and the Fundamental Research Funds for the Central Universities of China (Grant nos. N160103005 and N170108028). These supports are gratefully acknowledged.

\section{References}

[1] D. F. Malan and F. R. P. Basson, "Ultra-deep mining: the increased potential for squeezing conditions," Journal of South African Institute of Mining and Metallurgy, vol. 98, no. 7, pp. 353-363, 1998.

[2] Y. Potvin, J. Hadjigeorgiou, and D. Stacey, Challenges in Deep and High Stress Mining, Australian Center for Geomechanics, Crawley, Australia, 2007.

[3] S. R. Hu, J. C. Peng, C. Huang, P. I. Chen, and M. Li, "An overview of current status and progress in coal mining of the deep over a kilometer," China Mining Magazine, vol. 20, no. 7, pp. 105-110, 2011, in Chinese.

[4] M. C. He, H. P. Xie, S. P. Peng, and Y. D. Jiang, "Study on rock mechanics in deep mining engineering," Chinese Journal of Rock Mechanics and Engineering, vol. 24, no. 16, pp. 2803-2813, 2005, in Chinese.

[5] W. Müller, "Numerical simulation of rock bursts," Mining Science and Technology, vol. 12, no. 1, pp. 27-42, 1991.

[6] V. A. Mansurov, "Prediction of rockbursts by analysis of induced seismicity data," International Journal of Rock Mechanics and Mining Sciences, vol. 38, no. 6, pp. 893-901, 2001. 
[7] Z. M. Xu and R. Q. Huang, "Relationship between rock burst and blasting," Chinese Journal of Rock Mechanics and Engineering, vol. 22, no. 3, pp. 414-419, 2003, in Chinese.

[8] W. C. Zhu, Z. H. Li, L. Zhu, and C. A. Tang, "Numerical simulation on rockburst of underground opening triggered by dynamic disturbance," Tunnelling and Underground Space Technology, vol. 25, no. 5, pp. 587-599, 2010.

[9] D. E. Grady and M. E. Kipp, "Continuum modelling of explosive fracture in oil shale," International Journal of Rock Mechanics and Mining Sciences \& Geomechanics Abstracts, vol. 17, no. 3, pp. 147-157, 1980.

[10] W. B. Lu, J. H. Yang, P. Yan et al., "Dynamic response of rock mass induced by the transient release of in-situ stress," International Journal of Rock Mechanics and Mining Sciences, vol. 53, pp. 129-141, 2012.

[11] B. H. G. Brady and E. T. Brown, Rock Mechanics for Underground Mining, Kluwer Academic Publisher, New York, 2006.

[12] P. Jia and W. C. Zhu, "Dynamic-static coupling analysis on rockburst mechanism in jointed rock mass," Journal of Central South University, vol. 19, no. 11, pp. 3285-3290, 2012.

[13] D. F. Malan, "Time-dependent behaviour of deep level tabular excavations in hard rock," Rock Mechanics and Rock Engineering, vol. 32, no. 2, pp. 123-155, 1999.

[14] M. Cai, P. K. Kaiser, F. Suorineni, and K. Su, "A study on the dynamic behavior of the Meuse/Haute-Marne argillite," Physics and Chemistry of the Earth, Parts $A / B / C$, vol. 32, no. 8-14, pp. 907-916, 2007.

[15] Q. B. Zhang and J. Zhao, "A review of dynamic experimental techniques and mechanical behaviour of rock materials," Rock Mechanics and Rock Engineering, vol. 47, no. 4, pp. 1411-1478, 2014.

[16] R. Ulusay, The ISRM Suggested Methods for Rock Characterization, Testing and Monitoring: 2007-2014, Springer, Berlin, Germany, 2015.

[17] E. Hoek, Practical Rock Engineering, Rocscience, Inc., Toronto, Canada, 2007.

[18] M. Cai, "Influence of stress path on tunnel excavation response-numerical tool selection and modeling strategy," Tunnelling and Underground Space Technology, vol. 23, no. 6, pp. 618-628, 2008.

[19] K. Mogi, "Experimental study of deformation and fracture of marble: 1st paper on the fluctuation of compression strength of marble and the relation to the rate of stress application," Bulletin of Earthquake Research Institute, University of Tokyo, vol. 37, no. 1, pp. 155-170, 1959.

[20] J. C. Jaeger, "The frictional properties of joints in rock," Geofisica Pura E Applicata, vol. 43, no. 1, pp. 148-158, 1959.

[21] R. F. Blanks and D. McHenry, "Large triaxial testing machine built by Bureau of Reclamation," Engineering News Record, vol. 135, no. 6, pp. 171-172, 1945.

[22] M. Rocha, J. L. Serafim, A. Silveira, and J. R. Neto, "Deformability of foundation rocks," in Proceedings of 5th Congress on Large Dams, pp. 531-559, Paris, France, May 1955.

[23] K. W. John, "An approach to rock mechanics," Journal of the Soil Mechanics and Foundations Division, vol. 88, no. 4, pp. 1-30, 1962.

[24] F. L. L. B. Carneiro, "A new method to determine the tensile strength of concrete," in Proceedings of 5th Meeting of the Brazilian Association for Technical Rules, pp. 126-129, Sao Paulo, Brazil, September 1943.

[25] N. G. W. Cook, "The failure of rock," International Journal of Rock Mechanics and Mining Sciences \& Geomechanics Abstracts, vol. 2, no. 4, pp. 389-403, 1965.
[26] R. Ulusay and J. A. Hudson, "The complete ISRM suggested methods for rock characterization, testing and monitoring: 1974-2006," in Commission on Testing Methods, International Society for Rock Mechanics, Salzburg, Austria, 2007.

[27] L. R. Jing, "A review of techniques, advances and outstanding issues in numerical modelling for rock mechanics and rock engineering," International Journal of Rock Mechanics and Mining Sciences, vol. 40, no. 3, pp. 283-353, 2003.

[28] C. A. Tang, "Numerical simulation of progressive rock failure and associated seismicity," International Journal of Rock Mechanics and Mining Sciences, vol. 34, no. 2, pp. 249-261, 1997.

[29] G. W. Ma, X. M. An, and L. He, "The numerical manifold method: a review," International Journal of Computational Methods, vol. 7, no. 1, pp. 1-32, 2010.

[30] G. H. Shi, "Contact theory," Science China Technological Sciences, vol. 58, no. 9, pp. 1450-1496, 2015.

[31] H. Zheng and D. D. Xu, "New strategies for some issues of numerical manifold method in simulation of crack propagation," International Journal for Numerical Methods in Engineering, vol. 97, no. 13, pp. 986-1010, 2014.

[32] N. G. W. Cook, E. Hoek, J. P. G. Pretorius, W. D. Ortlepp, and M. D. G. Salamon, "Rock mechanics applied to the study of rockbursts," Journal of South African Institute of Mining and Metallurgy, vol. 66, no. 10, pp. 435-528, 1966.

[33] F. G. Hill, "An investigation into the problem of rock bursts," Journal of the Southern African Institute of Mining and Metallurgy, vol. 55, no. 4, pp. 63-72, 1954.

[34] J. T. M. Taylor, "Research on ground control and rockbursts on the Kolar Goldfield, India," Transactions of the Institution of Mining and Metallurgy, Section A: Mining Industry, vol. 72, pp. 317-338, 1962.

[35] S. D. Falls and R. P. Young, "Acoustic emission and ultrasonic-velocity methods used to characterise the excavation disturbance associated with deep tunnels in hard rock," Tectonophysics, vol. 289, no. 1-3, pp. 1-15, 1998.

[36] S. Pettitt, C. Baker, R. P. Young, L. O. Dahlström, and G. Ramqvist, "The assessment of damage around critical engineering structures using induced seismicity and ultrasonic techniques," Pure and Applied Geophysics, vol. 159, no. 1, pp. 179-195, 2002.

[37] T. Siren, P. Kantia, and M. Rinne, "Considerations and observations of stress-induced and construction-induced excavation damage zone in crystalline rock," International Journal of Rock Mechanics and Mining Sciences, vol. 73, pp. 165-174, 2015.

[38] M. Cai and P. K. Kaiser, "Assessment of excavation damaged zone using a micromechanics model," Tunnelling and Underground Space Technology, vol. 20, no. 4, pp. 301-310, 2005.

[39] J. B. Martino and N. A. Chandler, "Excavation-induced damage studies at the Underground Research Laboratory," International Journal of Rock Mechanics and Mining Sciences, vol. 41, no. 8, pp. 1413-1426, 2004.

[40] M. Souley, F. Homand, S. Pepa, and D. Hoxha, "Damageinduced permeability changes in granite: a case example at the URL in Canada," International Journal of Rock Mechanics and Mining Sciences, vol. 38, no. 2, pp. 297-310, 2001.

[41] T. Sato, T. Kikuchi, and K. Sugihara, "In-situ experiments on an excavation disturbed zone induced by mechanical excavation in Neogene sedimentary rock at Tono mine, central Japan," Engineering Geology, vol. 56, no. 1-2, pp. 97-108, 2000. 
[42] T. Iwatsuki, H. Hagiwara, K. Ohmori, T. Munemoto, and H. Onoe, "Hydrochemical disturbances measured in groundwater during the construction and operation of a large-scale underground facility in deep crystalline rock in Japan," Environmental Earth Sciences, vol. 74, no. 4, pp. 3041-3057, 2015.

[43] P. Bossart, P. M. Meier, A. Moeri, T. Trick, and J. C. Mayor, "Geological and hydraulic characterisation of the excavation disturbed zone in the Opalinus Clay of the Mont Terri Rock Laboratory," Engineering Geology, vol. 66, no. 1-2, pp. 19-38, 2002.

[44] A. Lisjak, B. Garitte, G. Grasselli, H. R. Müller, and T. Vietor, "The excavation of a circular tunnel in a bedded argillaceous rock (opalinus clay): short-term rock mass response and FDEM numerical analysis," Tunnelling and Underground Space Technology, vol. 45, pp. 227-248, 2015.

[45] A. Möri, W. R. Alexander, H. Geckeis et al., "The colloid and radionuclide retardation experiment at the grimsel test site: influence of bentonite colloids on radionuclide migration in a fractured rock," Colloids and Surfaces A: Physicochemical and Engineering Aspects, vol. 217, no. 1-3, pp. 33-47, 2003.

[46] J. D. Barnichon and G. Volckaert, "Observations and predictions of hydromechanical coupling effects in the Boom clay, Mol underground research laboratory, Belgium," Hydrogeology Journal, vol. 11, no. 1, pp. 193-202, 2003.

[47] L. Q. Dao, Y. J. Cui, A. M. Tang, J. M. Pereira, X. L. Li, and $\mathrm{X}$. Sillen, "Impact of excavation damage on the thermohydro- mechanical properties of natural Boom Clay," Engineering Geology, vol. 195, pp. 196-205, 2015.

[48] G. Armand, F. Leveau, C. Nussbaum et al., "Geometry and properties of the excavation-induced fractures at the meuse/ haute-marne URL drifts," Rock Mechanics and Rock Engineering, vol. 47, no. 1, pp. 21-41, 2014.

[49] M. Souley, G. Armand, and J. B. Kazmierczak, "Hydro-elastoviscoplastic modeling of a drift at the Meuse/Haute-Marne underground research laboratoratory (URL)," Computers and Geotechnics, vol. 85, pp. 306-320, 2017.

[50] X. T. Feng, B. R. Chen, S. J. Li et al., "Studies on the evolution process of rockbursts in deep tunnels," Journal of Rock Mechanics and Geotechnical Engineering, vol. 4, no. 4, pp. 289-295, 2012.

[51] C. A. Tang, J. M. Wang, and J. J. Zhang, "Preliminary engineering application of microseismic monitoring technique to rockburst prediction in tunneling of Jinping II project," Journal of Rock Mechanics and Geotechnical Engineering, vol. 2, no. 3, pp. 193-208, 2010.

[52] J. E. Field, S. M. Walley, W. G. Proud, H. T. Goldrein, and C. R. Siviour, "Review of experimental techniques for high rate deformation and shock studies," International Journal of Impact Engineering, vol. 30, no. 7, pp. 725-775, 2004.

[53] B. A. Gama, S. L. Lopatnikov, and J. J. W. Gillespie, "Hopkinson bar experimental technique: a critical review," Applied Mechanics Reviews, vol. 57, no. 4, pp. 223-250, 2004.

[54] K. T. Ramesh, "High rates and impact experiments," in Springer Handbook of Experimental Solid Mechanics, pp. 929-960, Springer, Berlin, Germany, 2008.

[55] K. W. Xia and W. Yao, "Dynamic rock tests using split Hopkinson (Kolsky) bar system-a review," Journal of Rock Mechanics and Geotechnical Engineering, vol. 7, no. 1, pp. 27-59, 2015.

[56] H. G. Kolsky, "An investigation of the mechanical properties of materials at very high rates of loading," Proceedings of the Physical Society. Section B, vol. 62, no. 11, pp. 676-700, 1949.
[57] R. M. Davies, "A critical study of the Hopkinson pressure bar," Philosophical Transactions of the Royal Society A: Mathematical, Physical and Engineering Sciences, vol. 240, no. 821, pp. 375-457, 1948.

[58] J. M. Krafft, A. M. Sullivan, and C. F. H. Tipper, "The effect of static and dynamic loading and temperature on the yield stress of iron and mild steel in compression," Proceedings of The Royal Society A: Mathematical, Physical and Engineering Sciences, vol. 221, no. 1144, pp. 114-127, 1954.

[59] U. S. Lindholm, "Some experiments with the split Hopkinson pressure bar," Journal of the Mechanics and Physics of Solids, vol. 12, no. 5, pp. 317-335, 1964.

[60] Y. X. Zhou, K. Xia, X. B. Li et al., "Suggested methods for determining the dynamic strength parameters and mode-I fracture toughness of rock materials," International Journal of Rock Mechanics and Mining Sciences, vol. 49, pp. 105-112, 2012.

[61] E. D. H. Davies and S. C. Hunter, "The dynamic compression testing of solids by the method of the split Hopkinson pressure bar," Journal of the Mechanics and Physics of Solids, vol. 11, no. 3, pp. 155-179, 1963.

[62] M. Zhang, H. J. Wu, Q. M. Li, and F. L. Huang, "Further investigation on the dynamic compressive strength enhancement of concrete-like materials based on split Hopkinson pressure bar tests. Part I: experiments," International Journal of Impact Engineering, vol. 36, no. 12, pp. 1327-1334, 2009.

[63] M. J. Forrestal, T. W. Wright, and W. Chen, "The effect of radial inertia on brittle samples during the split Hopkinson pressure bar test," International Journal of Impact Engineering, vol. 34, no. 3, pp. 405-411, 2007.

[64] Q. M. Li, Y. B. Lu, and H. Meng, "Further investigation on the dynamic compressive strength enhancement of concretelike materials based on split Hopkinson pressure bar tests. Part II: Numerical simulations," International Journal of Impact Engineering, vol. 36, no. 12, pp. 1335-1345, 2009.

[65] Q. M. Li and H. Meng, "About the dynamic strength enhancement of concrete-like materials in a split Hopkinson pressure bar test," International Journal of Solids and Structures, vol. 40, no. 2, pp. 343-360, 2003.

[66] Y. B. Lu, Q. M. Li, and G. W. Ma, "Numerical investigation of the dynamic compressive strength of rocks based on split Hopkinson pressure bar tests," International Journal of Rock Mechanics and Mining Sciences, vol. 47, no. 5, pp. 829-838, 2010.

[67] G. T. Gray, "Classic split-Hopkinson pressure bar testing," ASM Handbook, vol. 8, pp. 462-476, 2000.

[68] F. Dai, S. Huang, K. W. Xia, and Z. Y. Tan, "Some fundamental issues in dynamic compression and tension tests of rocks using split Hopkinson pressure bar," Rock Mechanics and Rock Engineering, vol. 43, no. 6, pp. 657-666, 2010.

[69] J. F. Bell, "An experimental diffraction grating study of the quasi-static hypothesis of the split hopkinson bar experiment," Journal of the Mechanics and Physics of Solids, vol. 14, no. 6, pp. 309-327, 1966.

[70] M. Alves, D. Karagiozova, G. B. Micheli, and M. A. G. Calle, "Limiting the influence of friction on the split Hopkinson pressure bar tests by using a ring specimen," International Journal of Impact Engineering, vol. 49, pp. 130-141, 2012.

[71] R. S. Hartley, T. J. Cloete, and G. N. Nurick, "An experimental assessment of friction effects in the split Hopkinson pressure bar using the ring compression test," International Journal of Impact Engineering, vol. 34, no. 10, pp. 1705-1728, 2007, in Chinese. 
[72] J. C. Gong, L. E. Malvern, and D. A. Jenkins, "Dispersion investigation in the split Hopkinson pressure bar," Journal of Engineering Materials and Technology, vol. 112, no. 3, pp. 309-314, 1990.

[73] D. A. Gorham, "A numerical method for the correction of dispersion in pressure bar signals," Journal of Physics E: Scientific Instruments, vol. 16, no. 6, pp. 477-479, 1983.

[74] X. B. Li, T. S. Lok, J. Zhao, and P. J. Zhao, "Oscillation elimination in the Hopkinson bar apparatus and resultant complete dynamic stress-strain curves for rocks," International Journal of Rock Mechanics and Mining Sciences, vol. 37, no. 7, pp. 1055-1060, 2000.

[75] D. J. Frew, M. J. Forrestal, and W. Chen, "A split Hopkinson pressure bar technique to determine compressive stressstrain data for rock materials," Experimental Mechanics, vol. 41, no. 1, pp. 40-46, 2001.

[76] D. J. Frew, M. J. Forrestal, and W. Chen, "Pulse shaping techniques for testing brittle materials with a split hopkinson pressure bar," Experimental Mechanics, vol. 42, no. 1, pp. 93-106, 2002.

[77] R. Gerlach, S. K. Sathianathan, C. Siviour, and N. Petrinic, "A novel method for pulse shaping of split Hopkinson tensile bar signals," International Journal of Impact Engineering, vol. 38, no. 12, pp. 976-980, 2011.

[78] S. Ellwood, L. J. Griffiths, and D. J. Parry, "Materials testing at high constant strain rates," Journal of Physics E: Scientific Instruments, vol. 15, no. 3, pp. 280-282, 1982.

[79] J. Lankford, "The role of tensile microfracture in the strain rate dependence of compressive strenght of fine-grained limestone-analogy with strong ceramics," International Journal of Rock Mechanics and Mining Sciences \& Geomechanics Abstracts, vol. 18, no. 2, pp. 173-175, 1981.

[80] G. W. Ma, J. C. Li, and J. Zhao, "Three-phase medium model for filled rock joint and interaction with stress waves," International Journal for Numerical and Analytical Methods in Geomechanics, vol. 35, no. 1, pp. 97-110, 2011.

[81] Z. L. Zhou, X. Cai, W. Z. Cao, X. B. Li, and C. Xiong, "Influence of water content on mechanical properties of rock in both saturation and drying processes," Rock Mechanics and Rock Engineering, vol. 49, no. 8, pp. 3009-3025, 2016.

[82] C. J. Zou and L. N. Y. Wong, "Experimental studies on cracking processes and failure in marble under dynamic loading," Engineering Geology, vol. 173, pp. 19-31, 2014.

[83] F. Dai and K. Xia, "Loading rate dependence of tensile strength anisotropy of barre granite," Pure and Applied Geophysics, vol. 167, no. 11, pp. 1419-1432, 2010.

[84] J. T. Gomez, A. Shukla, and A. Sharma, "Static and dynamic behavior of concrete and granite in tension with damage," Theoretical and Applied Fracture Mechanics, vol. 36, no. 1, pp. 37-49, 2001.

[85] Q. Z. Wang, W. Li, and X. L. Song, "A method for testing dynamic tensile strength and elastic modulus of rock materials using SHPB," Pure and Applied Geophysics, vol. 163, no. 5-6, pp. 1091-1100, 2006.

[86] J. Zhao and H. B. Li, "Experimental determination of dynamic tensile properties of a granite," International Journal of Rock Mechanics and Mining Sciences, vol. 37, no. 5, pp. 861-866, 2000.

[87] F. Dai, K. Xia, J. P. Zuo, R. Zhang, and N. W. Xu, "Static and dynamic flexural strength anisotropy of Barre granite," Rock Mechanics and Rock Engineering, vol. 46, no. 6, pp. 15891602, 2013.

[88] W. Goldsmith, J. L. Sackman, and C. Ewerts, "Static and dynamic fracture strength of Barre granite," International
Journal of Rock Mechanics and Mining Sciences \& Geomechanics Abstracts, vol. 13, no. 11, pp. 303-309, 1976.

[89] P. D. Zhao, F. Y. Lu, R. Chen et al., "A new technique for combined dynamic compression-shear test," in Proceedings of the 2010 Annual Conference on Experimental and Applied Mechanics, pp. 417-424, Springer New York, New York, NY, USA, June 2011.

[90] W. N. Chen and G. Ravichandran, "Dynamic compressive failure of a glass ceramic under lateral confinement," Journal of the Mechanics and Physics of Solids, vol. 45, no. 8, pp. 1303-1328, 1997.

[91] G. Gary and P. Bailly, "Behaviour of quasi-brittle material at high strain rate. Experiment and modelling," European Journal of Mechanics-A/Solids, vol. 17, no. 3, pp. 403-420, 1998.

[92] Z. T. Bieniawski, "Fracture dynamics of rock," International Journal of Fracture Mechanics, vol. 4, no. 4, pp. 415-430, 1968.

[93] R. Chen, K. Xia, F. Dai, F. Lu, and S. N. Luo, "Determination of dynamic fracture parameters using a semi-circular bend technique in split Hopkinson pressure bar testing," Engineering Fracture Mechanics, vol. 76, no. 9, pp. 1268-1276, 2009.

[94] F. Dai, Y. Xu, T. Zhao, N. W. Xu, and Y. Liu, "Loading-ratedependent progressive fracturing of cracked chevronnotched Brazilian disc specimens in split Hopkinson pressure bar tests," International Journal of Rock Mechanics and Mining Sciences, vol. 88, pp. 49-60, 2016.

[95] Y. Liu, F. Dai, P. Fan, N. Xu, and L. Dong, "Experimental investigation of the influence of joint geometric configurations on the mechanical properties of intermittent jointed rock models under cyclic uniaxial compression," Rock Mechanics and Rock Engineering, vol. 50, no. 6, pp. 14531471, 2017.

[96] Y. Xu, F. Dai, N. W. Xu, and T. Zhao, "Numerical investigation of dynamic rock fracture toughness determination using a semi-circular bend specimen in split Hopkinson pressure bar testing," Rock Mechanics and Rock Engineering, vol. 49, no. 3, pp. 731-745, 2016.

[97] Y. Xu and F. Dai, "Dynamic response and failure mechanism of brittle rocks under combined compression-shear loading experiments," Rock Mechanics and Rock Engineering, vol. 51, no. 3, pp. 747-764, 2018.

[98] D. Asprone, E. Cadoni, and A. Prota, "Experimental analysis on tensile dynamic behavior of existing concrete under high strain rates," ACI Structural Journal, vol. 106, no. 1, pp. 106-113, 2009.

[99] C. A. Ross, P. Y. Thompson, and J. W. Tedesco, "SplitHopkinson pressure-bar tests on concrete and mortar in tension and compression," ACI Materials Journal, vol. 86, no. 5, pp. 475-481, 1989.

[100] S. Kubota, Y. Ogata, Y. Wada, G. Simangunsong, H. Shimada, and K. Matsui, "Estimation of dynamic tensile strength of sandstone," International Journal of Rock Mechanics and Mining Sciences, vol. 45, no. 3, pp. 397-406, 2008.

[101] W. C. Zhu, L. L. Niu, S. H. Li, and Z. H. Xu, "Dynamic Brazilian test of rock under intermediate strain rate: Pendulum hammer-driven SHPB test and numerical simulation," Rock Mechanics and Rock Engineering, vol. 48, no. 5, pp. 1867-1881, 2015.

[102] R. J. Christensen, S. R. Swanson, and W. S. Brown, "Splithopkinson-bar tests on rock under confining pressure," Experimental Mechanics, vol. 12, no. 11, pp. 508-513, 1972. 
[103] U. S. Lindholm, L. M. Yeakley, and A. Nagy, "The dynamic strength and fracture properties of dresser basalt," International Journal of Rock Mechanics and Mining Sciences \& Geomechanics Abstracts, vol. 11, no. 5, pp. 181-191, 1974.

[104] D. J. Frew, S. A. Akers, W. Chen, and M. L. Green, "Development of a dynamic triaxial Kolsky bar," Measurement Science and Technology, vol. 21, no. 10, article 105704, 2010.

[105] Y. J. Zuo, L. I. Xibing, C. A. Tang, Y. P. Zhang, M. A. Chunde, and C. B. Yan, "Experimental investigation on failure of rock subjected to 2D dynamic-static coupling loading," Chinese Journal of Rock Mechanics and Engineering, vol. 25, no. 9, pp. 1809-1820, 2006, in Chinese.

[106] X. B. Li, F. Q. Gong, M. Tao et al., "Failure mechanism and coupled static-dynamic loading theory in deep hard rock mining: a review," Journal of Rock Mechanics and Geotechnical Engineering, vol. 9, no. 4, pp. 767-782, 2017.

[107] X. B. Li, Z. L. Zhou, T. S. Lok, L. Hong, and T. B. Yin, "Innovative testing technique of rock subjected to coupled static and dynamic loads," International Journal of Rock Mechanics and Mining Sciences, vol. 45, no. 5, pp. 739-748, 2008.

[108] X. B. Li, Z. L. Zhou, Z. Y. Ye et al., "Study of rock mechanical characteristics under coupled static and dynamic loads," Chinese Journal of Rock Mechanics and Engineering, vol. 27, no. 7, pp. 1387-1395, 2008, in Chinese.

[109] D. L. Cui, Study of Rock Dynamical Characteristics and Rockburst Mechanism under Three-Dimensional Coupled Static-Dynamic Loads, Central South University, Changsha Shi, China, 2007, in Chinese.

[110] F. Q. Gong, X. B. Li, and X. L. Liu, "Preliminary experimental study of characteristics of rock subjected to 3D coupled static and dynamic loads," Chinese Journal of Rock Mechanics \& Engineering, vol. 30, no. 6, pp. 1179-1190, 2011, in Chinese.

[111] X. B. Li, Z. L. Zhou, F. J. Zhao et al., "Mechanical properties of rock under coupled static-dynamic loads," Journal of Rock Mechanics and Geotechnical Engineering, vol. 1, no. 1, pp. 41-47, 2009.

[112] W. C. Zhu, Y. Bai, X. B. Li, and L. L. Niu, "Numerical simulation on rock failure under combined static and dynamic loading during SHPB tests," International Journal of Impact Engineering, vol. 49, pp. 142-157, 2012.

[113] Z. L. Zhou, X. B. Li, Y. Zou, Y. H. Jiang, and G. N. Li, "Dynamic Brazilian tests of granite under coupled static and dynamic loads," Rock Mechanics and Rock Engineering, vol. 47, no. 2, pp. 495-505, 2014.

[114] B. B. Wu, R. Chen, and K. W. Xia, "Dynamic tensile failure of rocks under static pre-tension," International Journal of Rock Mechanics and Mining Sciences, vol. 80, pp. 12-18, 2015.

[115] X. H. Liu, F. Dai, R. Zhang, and J. F. Liu, "Static and dynamic uniaxial compression tests on coal rock considering the bedding directivity," Environmental Earth Sciences, vol. 73, no. 10, pp. 5933-5949, 2015.

[116] W. Wu, "Slip initiation of granular gouge friction in a rock discontinuity induced by static and dynamic loads," International Journal of Rock Mechanics and Mining Sciences, vol. 80, pp. 196-201, 2015.

[117] C. J. Zou, L. N. Y. Wong, J. J. Loo, and B. S. Gan, “Different mechanical and cracking behaviors of single-flawed brittle gypsum specimens under dynamic and quasi-static loadings," Engineering Geology, vol. 201, pp. 71-84, 2016.

[118] W. I. Duvall and T. C. Atchison, Rock Breakage by Explosives, Department of the Interior, Bureau of Mines, Washington, DC, USA, 1957.
[119] A. Starfield, "Strain wave theory in rock blasting," in Proceedings of 8th Symposium on Rock Mechanics, vol. 23, pp. 538-548, Minneapolis, MN, USA, September 1966.

[120] U. Langefors and B. Kihlström, The Modern Technique of Rock Blasting, Almquist and Wiksell, Stockholm, Sweden, 1963.

[121] S. S. Saluja, "Mechanism of rock failure under the action of explosives," in Proceedings of 9th U.S. Symposium on Rock Mechanics, pp. 297-319, Golden, Colorado, April 1967.

[122] H. K. Kutter and C. Fairhurst, "On the fracture process in blasting," International Journal of Rock Mechanics and Mining Sciences \& Geomechanics Abstracts, vol. 8, no. 3, pp. 181-202, 1971.

[123] F. V. Donzé, J. Bouchez, and S. A. Magnier, "Modeling fractures in rock blasting," International Journal of Rock Mechanics and Mining Sciences \& Geomechanics Abstracts, vol. 34, no. 8, pp. 1153-1163, 1997.

[124] T. N. Hagan, "Rock breakage by explosives," Acta Astronautica, vol. 6, no. 3-4, pp. 329-340, 1979.

[125] W. C. Zhu, C. H. Wei, S. Li, J. Wei, and M. S. Zhang, "Numerical modeling on destress blasting in coal seam for enhancing gas drainage," International Journal of Rock Mechanics and Mining Sciences, vol. 59, pp. 179-190, 2013.

[126] M. A. Cook, U. D. Cook, and R. B. Clay, "Behavior of rock during blasting," Transaction of Social Mining Engineering, vol. 10, no. 2, pp. 17-25, 1966.

[127] M. G. Abuov, S. M. Aitaliev, T. M. Ermekov, N. B. Zhanbyrbaev, and M. A. Kayupov, "Studies of the effect of dynamic processes during explosive break-out upon the roof of mining excavations," Soviet Mining Science, vol. 24, no. 6, pp. 581-590, 1988.

[128] X. P. Zhou and Q. H. Qian, "Zonal fracturing mechanism in deep tunnel," Chinese Journal of Rock Mechanics and Engineering, vol. 26, no. 5, pp. 877-885, 2007, in Chinese.

[129] S. C. Li, Q. H. Qian, and D. F. Zhang, "Analysis of dynamic and fractured phenomena for excavation process of deep tunnel," Chinese Journal of Rock Mechanics and Engineering, vol. 28, no. 10, pp. 2104-2112, 2009, in Chinese.

[130] M. Tao, X. B. Li, and D. Y. Li, "Rock failure induced by dynamic unloading under 3D stress state," Theoretical and Applied Fracture Mechanics, vol. 65, pp. 47-54, 2013.

[131] W. C. Zhu, J. Wei, J. Zhao, and L. L. Niu, "2D numerical simulation on excavation damaged zone induced by dynamic stress redistribution," Tunnelling and Underground Space Technology, vol. 43, pp. 315-326, 2014.

[132] Y. Fan, W. B. Lu, Y. H. Zhou, P. Yan, Z. D. Leng, and M. Chen, "Influence of tunneling methods on the strainburst characteristics during the excavation of deep rock masses," Engineering Geology, vol. 201, pp. 85-95, 2016.

[133] X. B. Li, W. Z. Cao, M. Tao, Z. L. Zhou, and Z. H. Chen, "Influence of unloading disturbance on adjacent tunnels," International Journal of Rock Mechanics and Mining Sciences, vol. 84, pp. 10-24, 2016.

[134] J. H. Yang, W. B. Lu, Q. H. Jiang, C. Yao, S. H. Jiang, and L. Tian, "A study on the vibration frequency of blasting excavation in highly stressed rock masses," Rock Mechanics and Rock Engineering, vol. 49, no. 7, pp. 2825-2843, 2016.

[135] O. R. Bergmann, J. W. Riggle, and F. C. Wu, "Model rock blasting-effect of explosives properties and other variables on blasting results," International Journal of Rock Mechanics and Mining Sciences \& Geomechanics Abstracts, vol. 10, no. 6, pp. 585-612, 1973. 
[136] W. L. Fourney, R. D. Dick, and K. R. Y. Simha, "Model study of crater blasting," Rock Mechanics and Rock Engineering, vol. 21, no. 3, pp. 183-205, 1988.

[137] R. Badal, "Controlled blasting in jointed rocks," International Journal of Rock Mechanics and Mining Sciences \& Geomechanics Abstracts, vol. 31, no. 1, pp. 79-84, 1994.

[138] S. H. Cho, Y. Nakamura, B. Mohanty, H. S. Yang, and K. Kaneko, "Numerical study of fracture plane control in laboratory-scale blasting," Engineering Fracture Mechanics, vol. 75, no. 13, pp. 3966-3984, 2008.

[139] D. Saiang, Behaviour of Blast-Induced Damaged Zone Around Underground Excavations in Hard Rock Mass, Lulea University of Technology, Luleå, Sweden, 2008.

[140] W. B. Lu, M. Chen, X. Geng, D. Q. Shu, and C. B. Zhou, "A study of excavation sequence and contour blasting method for underground powerhouses of hydropower stations," Tunnelling and Underground Space Technology, vol. 29, pp. 31-39, 2012.

[141] W. C. Zhu, D. Gai, C. H. Wei, and S. G. Li, "High-pressure air blasting experiments on concrete and implications for enhanced coal gas drainage," Journal of Natural Gas Science and Engineering, vol. 36, pp. 1253-1263, 2016.

[142] F. P. Zhang, J. Y. Peng, Z. G. Qiu, Q. K. Chen, Y. H. Li, and J. P. Liu, "Rock-like brittle material fragmentation under coupled static stress and spherical charge explosion," Engineering Geology, vol. 220, pp. 266-273, 2017.

[143] R. Yang, W. F. Bawden, and P. D. Katsabanis, "A new constitutive model for blast damage," International Journal of Rock Mechanics and Mining Sciences and Geomechanics Abstracts, vol. 33, no. 3, pp. 245-254, 1996.

[144] H. Hao, C. Wu, and Y. Zhou, "Numerical analysis of blastinduced stress waves in a rock mass with anisotropic continuum damage models part 1: equivalent material property approach," Rock Mechanics and Rock Engineering, vol. 35, no. 2, pp. 79-94, 2002.

[145] H. Ding and Z. M. Zheng, "Source model for blasting vibration," Science in China Series E: Technolgical Science, vol. 45, no. 4, pp. 395-407, 2002.

[146] Z. M. Zhu, B. Mohanty, and H. P. Xie, "Numerical investigation of blasting-induced crack initiation and propagation in rocks," International Journal of Rock Mechanics and Mining Sciences, vol. 44, no. 3, pp. 412-424, 2007.

[147] G. W. Ma and X. M. An, "Numerical simulation of blastinginduced rock fractures," International Journal of Rock Mechanics and Mining Sciences, vol. 45, no. 6, pp. 966-975, 2008.

[148] Y. J. Ning, J. Yang, X. M. An, and G. W. Ma, "Modelling rock fracturing and blast-induced rock mass failure via advanced discretisation within the discontinuous deformation analysis framework," Computers and Geotechnics, vol. 38, no. 1, pp. 40-49, 2011.

[149] O. Yilmaz and T. Unlu, "Three dimensional numerical rock damage analysis under blasting load," Tunnelling and Underground Space Technology, vol. 38, pp. 266-278, 2013.

[150] P. Yan, W. X. Zhou, W. B. Lu, M. Chen, and C. B. Zhou, "Simulation of bench blasting considering fragmentation size distribution," International Journal of Impact Engineering, vol. 90, pp. 132-145, 2016.

[151] H. M. An, H. Y. Liu, H. Han, X. Zheng, and X. G. Wang, "Hybrid finite-discrete element modelling of dynamic fracture and resultant fragment casting and muck-piling by rock blast," Computers and Geotechnics, vol. 81, pp. 322-345, 2017.
[152] Y. S. Li and C. C. Xia, "Time-dependent tests on intact rocks in uniaxial compression," International Journal of Rock Mechanics and Mining Sciences, vol. 37, no. 3, pp. 467-475, 2000.

[153] G. N. Boukharov, M. W. Chanda, and N. G. Boukharov, "The three processes of brittle crystalline rock creep," International Journal of Rock Mechanics and Mining Sciences \& Geomechanics Abstracts, vol. 32, no. 4, pp. 325-335, 1995.

[154] D. A. Lockner, "The role of acoustic emission in the study of rock fracture," International Journal of Rock Mechanics and Mining Science \& Geomechanics Abstracts, vol. 30, no. 7, pp. 883-899, 1993.

[155] C. H. Scholz, "Mechanism of creep in brittle rock," Journal of Geophysical Research, vol. 73, no. 10, pp. 3295-3302, 1968.

[156] D. A. Lockner, "Room temperature creep in saturated granite," Journal of Geophysical Research: Solid Earth, vol. 98, no. B1, pp. 475-487, 1993.

[157] B. T. Ngwenya, I. G. Main, S. C. Elphick, B. R. Crawford, and B. G. D. Smart, "A constitutive law for low-temperature creep of water-saturated sandstones," Journal of Geophysical Research: Solid Earth, vol. 106, no. B10, pp. 21811-21826, 2001.

[158] N. Brantut, M. J. Heap, P. Baud, and P. G. Meredith, "Rateand strain-dependent brittle deformation of rocks," Journal of Geophysical Research: Solid Earth, vol. 119, no. 3, pp. 1818-1836, 2014.

[159] A. Guarino, S. Ciliberto, A. Garcimartın, M. Zei, and R. Scorretti, "Failure time and critical behaviour of fracture precursors in heterogeneous materials," European Physical Journal B, vol. 26, no. 2, pp. 141-151, 2002.

[160] H. Nechad, A. Helmstetter, R. E. Guerjouma, and D. Sornette, "Creep ruptures in heterogeneous materials," Physical Review Letters, vol. 94, no. 4, article 045501, 2005.

[161] B. Voight, "A relation to describe rate-dependent material failure," Science, vol. 243, no. 4888, pp. 200-203, 1989.

[162] M. J. Heap, P. Baud, P. G. Meredith, S. Vinciguerra, A. F. Bell, and I. G. Main, "Brittle creep in basalt and its application to time-dependent volcano deformation," Earth and Planetary Science Letters, vol. 307, no. 1-2, pp. 71-82, 2011.

[163] I. G. Main, “A damage mechanics model for power-law creep and earthquake aftershock and foreshock sequences," Geophysical Journal International, vol. 142, no. 1, pp. 151-161, 2000.

[164] T. Akagi, Y. Ichikawa, H. Kuroda, and T. Kawamoto, "A non-linear rheological analysis of deeply located tunnels," International Journal for Numerical and Analytical Methods in Geomechanics, vol. 8, no. 5, pp. 457-471, 1984.

[165] P. Bérest, P. Antoine Blum, J. Pierre Charpentier, H. Gharbi, and F. Valès, "Very slow creep tests on rock samples," International Journal of Rock Mechanics and Mining Sciences, vol. 42, no. 4, pp. 569-576, 2005.

[166] G. Fabre and F. Pellet, "Creep and time-dependent damage in argillaceous rocks," International Journal of Rock Mechanics and Mining Sciences, vol. 43, no. 6, pp. 950-960, 2006.

[167] U. Hunsche and A. Hampel, "Rock salt-the mechanical properties of the host rock material for a radioactive waste repository," Engineering Geology, vol. 52, no. 3-4, pp. 271291, 1999.

[168] K. Masuda, H. Mizutani, and I. Yamada, "Experimental study of strain-rate dependence and pressure dependence of failure properties of granite," Journal of Physics of the Earth, vol. 35, no. 1, pp. 37-66, 1987. 
[169] S. Okubo, Y. Nishimatsu, and K. Fukui, "Complete creep curves under uniaxial compression," International Journal of Rock Mechanics and Mining Sciences \& Geomechanics Abstracts, vol. 28, no. 1, pp. 77-82, 1991.

[170] J. Slizowski and L. Lankof, "Salt-mudstones and rock-salt suitabilities for radioactive-waste storage systems: rheological properties," Applied Energy, vol. 75, no. 1-2, pp. 137-144, 2003.

[171] Ö. Aydan, T. Ito, U. Özbay et al., "ISRM suggested methods for determining the creep characteristics of rock," Rock Mechanics and Rock Engineering, vol. 47, no. 1, pp. 275-290, 2014.

[172] N. Brantut, M. J. Heap, P. G. Meredith, and P. Baud, “Timedependent cracking and brittle creep in crustal rocks: a review," Journal of Structural Geology, vol. 52, pp. 17-43, 2013.

[173] N. Challamel, C. Lanos, and C. Casandjian, "Creep damage modelling for quasi-brittle materials," European Journal of Mechanics-A/Solids, vol. 24, no. 4, pp. 593-613, 2005.

[174] A. A. Fakhimi and C. Fairhurst, "A model for the timedependent behavior of rock," International Journal of Rock Mechanics and Mining Sciences \& Geomechanics Abstracts, vol. 31, no. 2, pp. 117-126, 1994.

[175] D. F. Malan, "Manuel rocha medal recipient simulating the time-dependent behaviour of excavations in hard rock," Rock Mechanics and Rock Engineering, vol. 35, no. 4, pp. 225-254, 2002.

[176] D. A. Lockner, "A generalized law for brittle deformation of Westerly granite," Journal of Geophysical Research: Solid Earth, vol. 103, no. B3, pp. 5107-5123, 1998.

[177] H. Molladavoodi and A. Mortazavi, "A damage-based numerical analysis of brittle rocks failure mechanism," Finite Elements in Analysis and Design, vol. 47, no. 9, pp. 991-1003, 2011.

[178] J. F. Shao, Q. Z. Zhu, and K. Su, "Modeling of creep in rock materials in terms of material degradation," Computers and Geotechnics, vol. 30, no. 7, pp. 549-555, 2003.

[179] R. Shcherbakov and D. L. Turcotte, "Damage and selfsimilarity in fracture," Theoretical and Applied Fracture Mechanics, vol. 39, no. 3, pp. 245-258, 2003.

[180] B. Voight, "A method for prediction of volcanic eruptions," Nature, vol. 332, no. 6160, pp. 125-130, 1988.

[181] H. W. Zhou, C. P. Wang, B. B. Han, and Z. Q. Duan, “A creep constitutive model for salt rock based on fractional derivatives," International Journal of Rock Mechanics and Mining Sciences, vol. 48, no. 1, pp. 116-121, 2011.

[182] L. S. Tsai, Y. M. Hsieh, M. C. Weng, T. H. Huang, and F. S. Jeng, "Time-dependent deformation behaviors of weak sandstones," International Journal of Rock Mechanics and Mining Sciences, vol. 45, no. 2, pp. 144-154, 2008.

[183] L. S. Costin, "A microcrack model for the deformation and failure of brittle rock," Journal of Geophysical Research: Solid Earth, vol. 88, no. B11, pp. 9485-9492, 1983.

[184] J. M. Kemeny, "A model for non-linear rock deformation under compression due to sub-critical crack growth," International Journal of Rock Mechanics and Mining Sciences \& Geomechanics Abstracts, vol. 28, no. 6, pp. 459467, 1991.

[185] D. A. Lockner and T. R. Madden, "A multiple-crack model of brittle fracture: 2. time-dependent simulations," Journal of Geophysical Research: Solid Earth, vol. 96, no. B12, pp. 19643-19654, 1991.

[186] A. Golshani, M. Oda, Y. Okui, T. Takemura, and E. Munkhtogoo, "Numerical simulation of the excavation damaged zone around an opening in brittle rock," International Journal of Rock Mechanics and Mining Sciences, vol. 44, no. 6, pp. 835-845, 2007.

[187] H. Konietzky, A. Heftenberger, and M. Feige, "Life-time prediction for rocks under static compressive and tensile loads: a new simulation approach," Acta Geotechnica, vol. 4, no. 1, pp. 73-78, 2009.

[188] D. L. Turcotte, W. I. Newman, and R. Shcherbakov, "Micro and macroscopic models of rock fracture," Geophysical Journal International, vol. 152, no. 3, pp. 718-728, 2003.

[189] D. Amitrano and A. Helmstetter, "Brittle creep, damage, and time to failure in rocks," Journal of Geophysical Research: Solid Earth, vol. 111, no. B11, pp. 1-17, 2006.

[190] N. Brantut, P. Baud, M. J. Heap, and P. G. Meredith, "Micromechanics of brittle creep in rocks," Journal of Geophysical Research: Solid Earth, vol. 117, no. B8, pp. 1133-1172, 2012.

[191] M. F. Ashby and C. G. Sammis, "The damage mechanics of brittle solids in compression," Pure and Applied Geophysics PAGEOPH, vol. 133, no. 3, pp. 489-521, 1990.

[192] T. Xu, C. A. Tang, J. Zhao, L. C. Li, and M. J. Heap, "Modelling the time-dependent rheological behaviour of heterogeneous brittle rocks," Geophysical Journal International, vol. 189, no. 3, pp. 1781-1796, 2012.

[193] X. C. Zhang, The Mechanism of Rockburst in Mines and its Practices in the Prevention and Control, Southeast University Press, Nanjing, China, 2010, in Chinese.

[194] Z. H. Xu, X. H. Xu, and Z. H. Chen, "Cusp catastraphy and time effection of rock burst on an isolated coal pillar," West-China Exploration Engineering, vol. 8, no. 4, pp. 1-5, 1996.

[195] C. Y. Shi, Study on Rock Burst Tendentiousness and Monitoring Control in Hongtoushan Copper Mine, Northeastern University, Boston, MA, USA, 2008, in Chinese.

[196] B. R. Chen, X. T. Feng, H. J. Ming et al., "Evolution law and mechanism of rock burst in deep tunnel: time delayed rockburst," Chinese Journal of Rock Mechanics and Engineering, vol. 31, no. 3, pp. 561-569, 2012, in Chinese.

[197] P. Yan, Z. G. Zhao, W. B. Lu, Y. Fan, X. R. Chen, and Z. G. Shan, "Mitigation of rock burst events by blasting techniques during deep-tunnel excavation," Engineering Geology, vol. 188, pp. 126-136, 2015.

[198] Y. F. Gao, W. P. Huang, G. L. Qu, B. Wang, X. H. Cui, and Q. Z. Fan, "Perturbation effect of rock rheology under uniaxial compression," Journal of Central South University, vol. 24, no. 7, pp. 1684-1695, 2017.

[199] W. C. Zhu, S. Li, L. L. Niu, K. Liu, and T. Xu, "Experimental and numerical study on stress relaxation of sandstones disturbed by dynamic loading," Rock Mechanics and Rock Engineering, vol. 49, no. 10, pp. 3963-3982, 2016.

[200] S. P. Timoshenko and J. N. Goodier, Theory of Elasticity, Higher Education Press, Beijing, China, 2013, in Chinese.

[201] Q. Y. Wang, W. C. Zhu, T. Xu, L. L. Niu, and J. Wei, "Numerical simulation of rock creep behavior with a damage-based constitutive law," International Journal of Geomechanics, vol. 17, no. 1, article 04016044, 2017.

[202] H. Kraus, Creep Analysis, Wiley, Hoboken, NJ, USA, 1980.

[203] W. C. Zhu and C. A. Tang, "Micromechanical model for simulating the fracture process of rock," Rock Mechanics and Rock Engineering, vol. 37, no. 1, pp. 25-56, 2004.

[204] X. B. Li, F. Q. Gong, J. Zhao, G. Ke, and T. B. Yin, "Test study of impact failure of rock subjected to one-dimensional coupled static and dynamic loads," Chinese Journal of 
Rock Mechanics and Engineering, vol. 29, no. 2, pp. 251-260, 2010, in Chinese.

[205] J. Wei, W. C. Zhu, C. H. Wei, Y. Bai, and S. Li, "Numerical simulation on contribution of guide-hole to crack coalescence of two boreholes," Engineering Mechanics, vol. 30, no. 5, pp. 335-339, 2013, in Chinese.

[206] Y. Bai, W. C. Zhu, C. H. Wei, and J. Wei, "Numerical simulation on two-hole blasting under different in-situ stress conditions," Rock and Soil Mechanics, vol. 34, no. S1, pp. 466-471, 2013, in Chinese. 


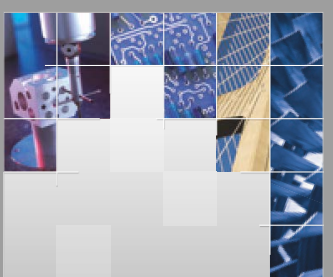

\section{Enfincering}
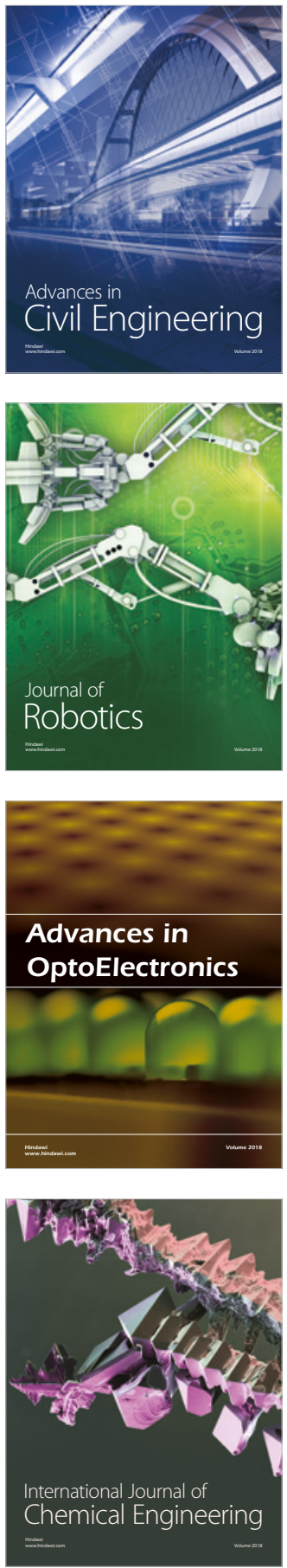

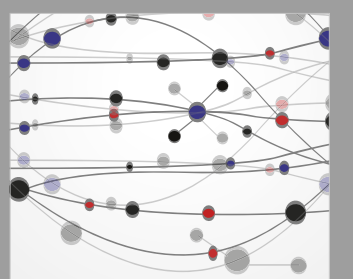

\section{Rotating \\ Machinery}

The Scientific World Journal

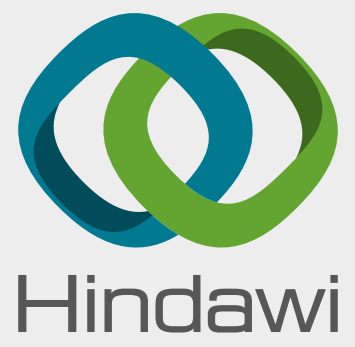

Submit your manuscripts at

www.hindawi.com
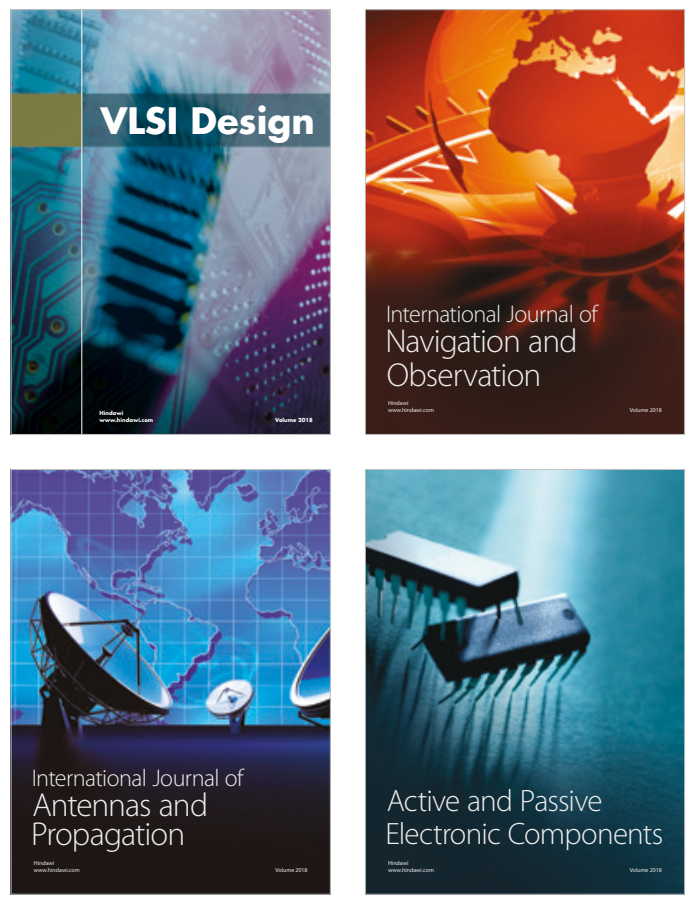
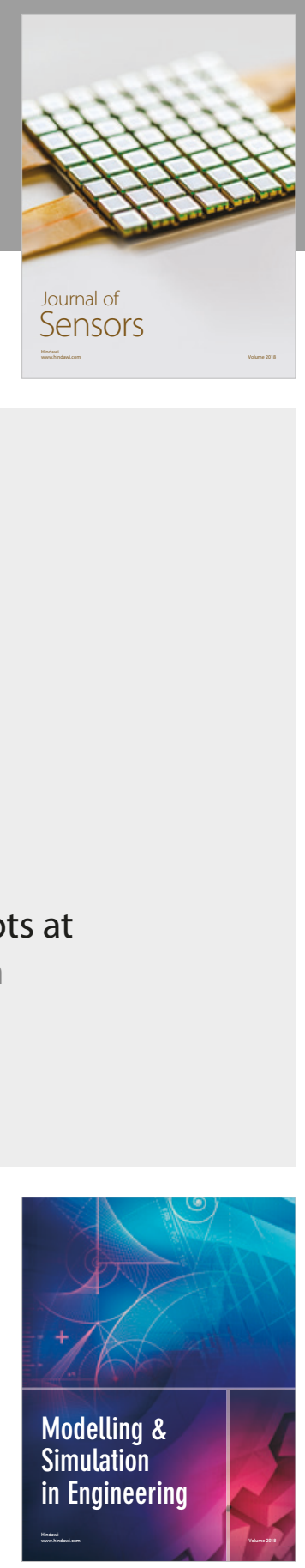

\section{Advances \\ Multimedia}
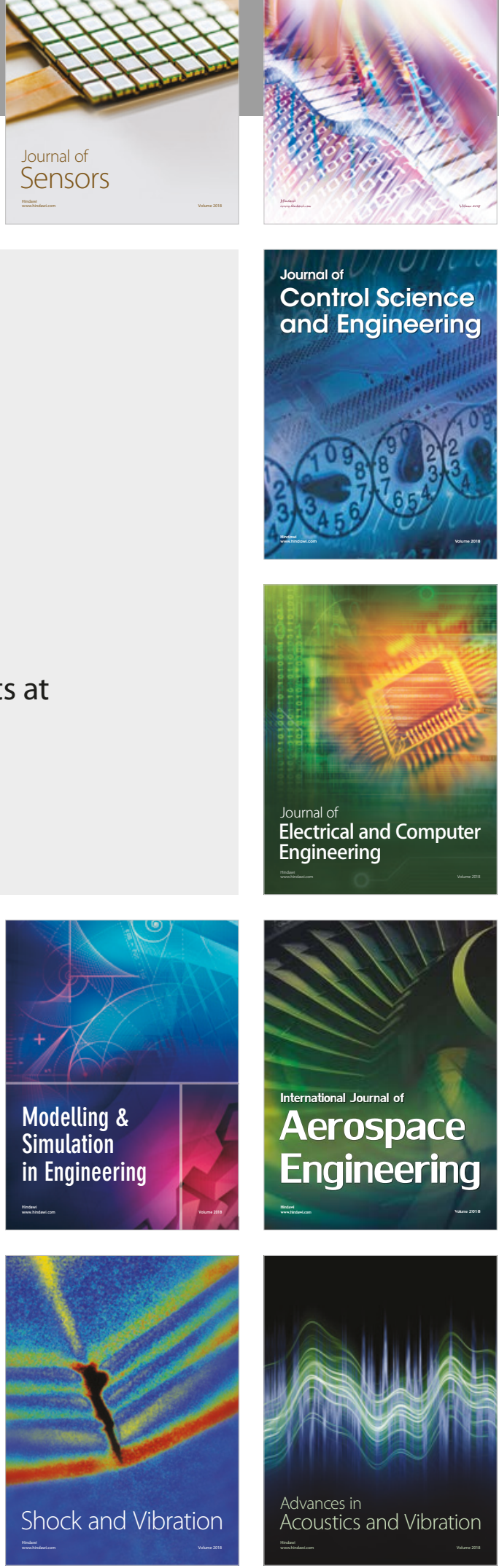